\title{
Multi-Criteria Decision-Making for Marine Propulsion: Hybrid, Diesel Electric and Diesel Mechanical Systems from Cost-
}

\section{Environment-Risk Perspectives}

\author{
Byongug Jeong *, Elif Oguz, Haibin Wang, Peilin Zhou \\ Department of Naval Architecture, Ocean and Marine Engineering, University of Strathclyde, 100 \\ Montrose Street, Glasgow, G4 OLZ, UK \\ *corresponding author; e-mail: byongug.jeong@strath.ac.uk
}

\begin{abstract}
The paper introduces a new decision-making process which is used to compare the performance of a ship with either diesel electric hybrid propulsion or conventional propulsion systems. A case study was carried out to compare the performance of both propulsions from cost, environmental and risk perspectives. This paper also overviews the modern approaches of multi-criteria decision-making and highlights some of their shortcomings in particular the fact that these approaches often rely on different criteria such as financial, environmental or risk. This paper aims to overcome this shortcoming by enhancing the process of multi-criteria decision analysis. The key process in this research was to convert all incomparable values into monetary values, thereby enabling the impacts of each criterion to be compared and integrated in a straightforward manner. Results of the case study showed that the use of a hybrid propulsion system could reduce annual operational costs by $\$ 300,000$ (2\% total cost) compared with a diesel electric system and almost $\$ 1$ million (7\%) compared to a diesel
\end{abstract}


mechanical propulsion system. In order to investigate the optimal use of the hybrid propulsion system, various operational scenarios were identified and applied to the proposed decision-making process. The results showed that operating the ship in hybrid mode during manoeuvring and berthing is more desirable as the holistic cost can reduce in almost $\$ 1$ million. The advantages of the proposed decision making process was illustrated by comparing the results obtained from a conventional decision-making process using the analytical hierarchical method. It is believed that the research findings not only present general understanding of the possible advantages of hybrid propulsion for stakeholders, but provide them with an insight into the enhanced approach into the multi-criteria decision analysis.

Keywords: Hybrid ship, Multi-criteria decision analysis, Hybrid propulsion, MCDA 


\section{List of symbols}

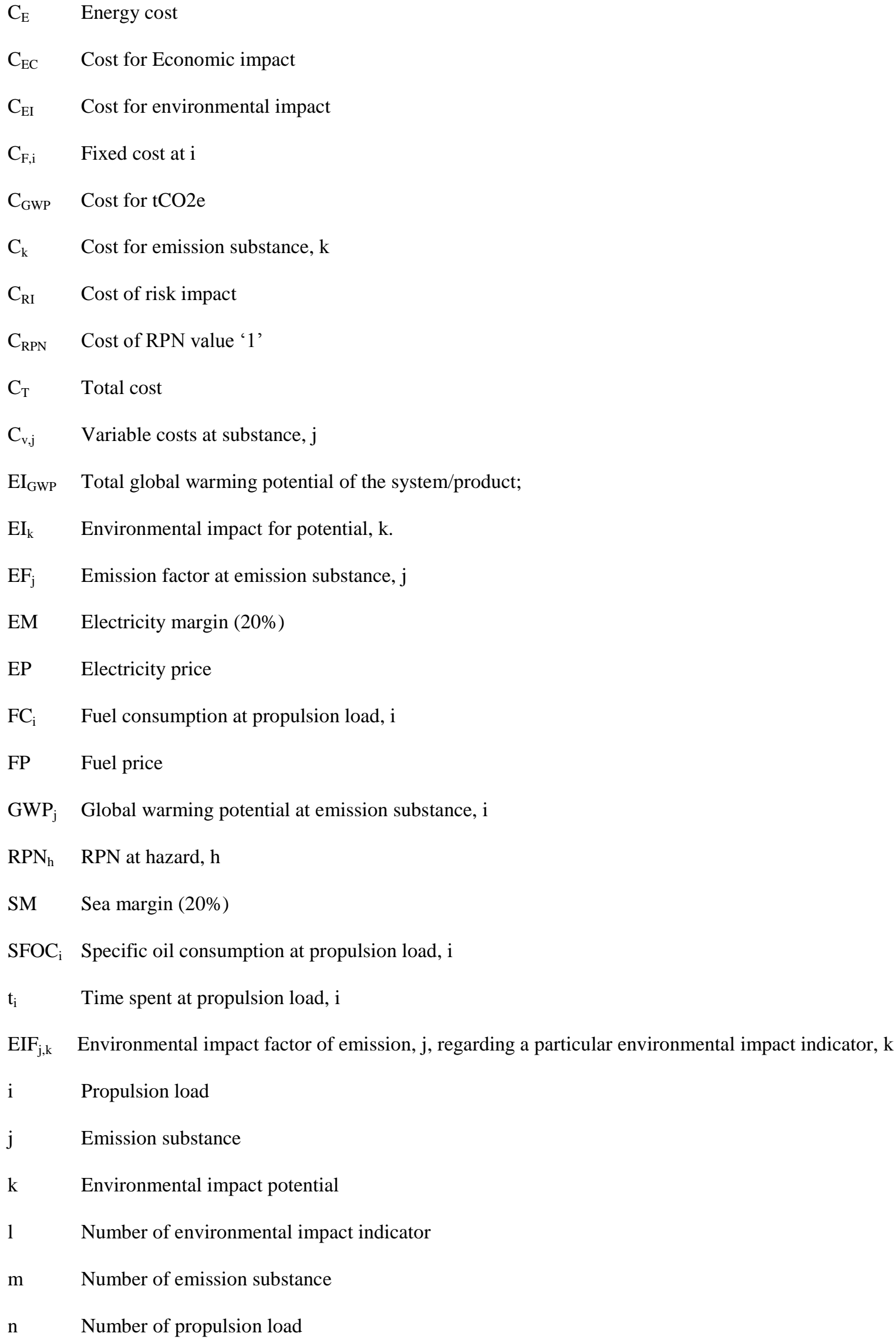




\section{Introduction}

\subsection{Overview of hybrid ships}

With an increasing demand to develop more efficient and cleaner ships, hybrid technology has drawn attention from the marine industry. Thanks to the breakthrough in battery technology which can improve the flexibility of selecting power sources, the last few years showed a number of developments in hybrid ships propulsion.

MV Viking Lady, the world's first hybrid ship equipped with a $500 \mathrm{kWh}$ battery system, was launched in 2013 [1]. A series of hybrid ships followed on from this; the new offshore supply vessel of MV Edda Ferd was constructed in 2013 which was the first large electric batterypowered car ferry, MV Ampere, was delivered in 2015 [2]. For UK domestic services, three hybrid ro-ro passenger ferries, namely $M V$ Lochinvar, $M V$ Hallaig, and $M V$ Catriona, were built between 2011 and 2016. They are currently in operation in Scotland [3].

Various industrial reports and academic research have showed that hybrid ships will contribute to greener shipping.

Lindstad and Sandaas [4] investigated the environmental advantage of hybrid offshore support vessels with dynamic positioning system, compared with a conventional diesel electrical system. Ling-Chin and Roskilly [5] introduced a new life cycle assessment (LCA) approach in order to evaluate the performance of a hybrid ro-ro cargo vessel in terms of environmental impact, whereas Dedes et al. [6] investigated the economic impact of the hybrid system for slow speed ocean-going ships in terms of fuel saving. In addition, Wang et al. [7] adopted life cycle assessment (LCA) and life cycle cost analysis (LCCA) methods for a short route hybrid ferry and pointed out that hybrid systems in collaboration 
with main and auxiliary engines could contribute to a significant reduction in fuel consumption.

Lan et al. [8] proposed a structured model for estimating the optimal size of hybrid propulsion systems consisting of photovoltaic (PV), diesel engine and battery systems for five voyage scenarios.

Wen et al. [9] developed an interval method to determine the optimal size of an energy storage system (ESS) combined with a photovoltaic power system. The results obtained from a wide range of engine loads were compared from economic and environmental perspectives.

Diab et al. [10] compared onshore hybrid renewable systems with the equivalent sets of on-board systems, revealing that the combination of solar and battery systems can improve the efficiency of ship performance.

Geertsma et al. [11] reviewed recent developments in propulsion, power supply systems and their control strategies while discussing opportunities and challenges for these systems and controls. Their findings illustrated that hybrid structures with advanced control strategies could reduce fuel consumption and emissions up to $10-35 \%$ with the enhancement of noise, maintainability, manoeuvrability and comfort.

Geertsma et al. [12-13] introduced an electric drive model and integrated into the mechanical propulsion model introduced, whereas Veneri et al. [14] reviewed a number of naval applications from traditional to more innovative electric propulsion and generation architectures.

Roskilly et al. [15] showed that significant reduction in both $\mathrm{CO}_{2}$ and $\mathrm{NO}_{\mathrm{x}}$ emissions could be achieved through the life cycle and cost analyses for hybrid propulsion systems. To reduce propulsion power loss, Zhao et al. [16] suggested an optimal power management for ship propulsion system concerning improving efficiency while reducing 
emissions. Aneke and Wang [17] reviewed energy storage technologies applicable to the hybrid ships. Jeong et al. [18] illustrated the advantages of a hybrid ship by comparing its performance with equivalent ships with diesel-electric and diesel-mechanical propulsion systems. They also presented an enhanced framework to investigate the holistic cost and environmental impacts of marine vessels.

In addition to the marine industry, several research carried out to introduce the importance of new incentives for replacing diesel vehicles with hybrid/electric vehicles. Palmer et al. [19] carried out a study to determine the total cost of ownership, which combines purchase and operating expenses, of hybrid and electric vehicles in the UK, US and Japan in order to identify the most economical choice of vehicle.

With a remarkable advancement in hybrid-electric powertrain technology to automotive industry, some powertrain designs were suggested by researchers. Hutchinson et al. [20] evaluated architecture designs and empirical analysis of whole-life costing. Their findings showed that the value of hybrid powertrains would be dependent on the vehicle's application considering market conditions and manner of use.

Despite the optimistic prospect of the hybrid ship, previous research has lacked systematic investigations into whether hybrid ships are a good choice over conventional ship propulsion types. Ship hybrid propulsion is a relatively new concept in the industry, consequently, there are still many unknowns in terms of optimal design and operational practices. This inspired this paper to investigate the holistic performance of hybrid ships. 


\subsection{Overview of multi-criteria decision-making processes}

Proper decision-making plays an important part in a successful business across many different industries. For a single criterion, the decision can be made simply by comparing the value of the criterion obtained from the base option with equivalent sets of alternatives. In real business where multiple criteria have to be considered, the added complexity of multidimensionality has to be considered [21].

Over the years several multi-criteria decision analysis (MCDA) methods have been developed. In particular, Multi-Attribute Utility Theory (MAUT), Analytical Hierarchy Process (AHP) and Outranking are regarded as some of the most commonly used MCDA methods [22-29].

In addition to these, various enhanced approaches to MCDA have been recently introduced. Linkov and Seager [30] developed a concept of coupling MCDA that would account for environmental and risk impacts in relation to emerging threats in the medical industry. This approach integrated the impact of each category, enabling a base design to be compared with alternatives. They showed the coupling of the risk assessment with life cycle assessment could enhance the management of risk.

Basurko and Mesbahi [31] presented an integrated quantitative approach for the holistic assessment of a number of marine technologies considering economic, environmental, and social sustainability. The analysis was carried out by means of standard life cycle assessment and economic assessment methods, coupled with a new method for evaluating the risk impact.

Niekamp et al. [32] structured a framework for multi-criteria decision making in relation to the sustainability of asset management. With the proposed method, decision-makers can assign certain levels of weight to the scores on each criterion based on their own knowledge 
or preference. This method was applied to a case study on evaluating the advantages and disadvantages of material alternatives, compared to the conventional carbon steel.

In order to evaluate the optimal cost-effective measures for reducing marine pollution, Yuan and $\mathrm{Ng}$ [33] introduced a ranking algorithm that was later applied for ranking credible emission-reducing measures. Dong et al. [34] evaluated the optimal municipal waste management system in the viewpoint of energy efficiency, environmental friendliness and economic feasibility. On the other hand, the approach to weighing factors on various criteria has been extensively used; to investigate the optimal wind farm siting [35-36]; to optimize biomass briquette fuel system [37]; to investigate optimal siting and size of bioenergy facilities [38-39]; to apply environmental criteria to assess the performance of product suppliers [40-41].

\subsection{Limitations of conventional MCDA}

In the conventional MCDA, the process of normalization and weighing factors may be an unwanted but a compulsory process in order to compare incomparable units across the indexes. The role of weighting factors is to compensate for the influence of uncertainties, which may be caused by consolidating complex information into a value-less number, on the results.

After reviewing previous research, a number of drawbacks of conventional MCDA are identified. As an integration process across the impacts from multi-criteria decision, certain levels of weighting factors are given to each criterion as a form of 'relative ratio' based on user's own knowledge or preference. The results of such analytic approach are destined to overly rely on what values are weighted on each criterion. Therefore, the over reliance on personal subjectivity may lead to a wrong conclusion, and/or diminish the reliability of 
results. Therefore, the adequacy and inadequacy of weighting factors on particular criteria are still needed to be studied.

Wang et al. [42] investigated the influence of factors weighted on different criteria on the MCDA for a sustainable energy selection, taking into account the multi-dimensional nature of sustainability goals in terms of complexity of socio-economic and biophysical systems.

In addition, the key challenge to assign weighting factors for different categories based on the subjective information provided by stakeholders was addressed by a number of research [4346]. Since 1979 when Dawes [47] addressed that the results would be biased by weighing methods, the practice of giving equal weights to each category has been widely adopted as a stopgap. However, this practice is still subjected to the loss of information during the normalization process to converge different units into a compatible one. To make the analysis more reliable, an enhanced approach may be required.

Wheelan [21] also addressed the disadvantage of normalizing any index since it consolidates lots of complex information into a single number. Regarding the process of weighing factors, there are a great number of ways to produce a different outcome. He described this by giving an example of car and driver's ranking of three sports cars: the Porsche Cayman, the Chevrolet Corvette, and the Lotus Evora. Using a formula that includes twenty-one different variables, the company ranked the Porsche number one. However, it was pointed out that "exterior styling" counted for only four percent of the total score in the Car and Driver formula, which seemed ridiculously low for a sports car. On the other hand, when styling was given more weight in the overall ranging ( $25 \%)$, the Lotus was turned out on top. Likewise, when the sticker price was weighted more heavily, the Chevy Corvetter was ranked number one.

It shows that any criterion is highly sensitive to the weight given to each of those components. Conventional MCDA approach is technically and academically correct and yet 
somewhat is not fully correct in terms of purpose to provide a reliable answer to the real world.

\subsection{Research motivation}

This paper was aimed to enhance the general understanding of the differential performance of three replaceable marine propulsion systems in the economic, environmental and risk aspects. The impact of one criterion is inherently expressed in a different format from the others, thereby the direct combination and/or straightforward comparison may not be possible. For instance, the basic unit of economic impact can be represented as monetary value, whereas those of environmental and risk impacts may be quantified to be the amount of air emissions and risk level respectively.

In this context, the key lesson from the previous research is to pay attention to the disparity in the unit of analysis. In this regard, the focus of this paper was placed on developing an enhanced approach to the optimal decision-making for propulsion system selection. The primary idea of the proposed approach was to unify all the impact values as equivalent monetary values, thereby the negative effect of weighing factors on each criterion, influencing users' preference on the final results, can be eliminated. This theory was applied to illustrate the performance of a hybrid ro-ro ferry, $M V$ Catriona, in comparison with the conventional propulsion types: diesel electric (DE) and diesel mechanical (DM) systems.

\section{Description of proposed approach}

Taking into account the background and limitations of the conventional decision-making approaches, 
Fig. 1 outlines the proposed decision-making framework in which economic, environmental and risk impacts are individually assessed. The impact levels of each criterion are, then, converted into monetary values in order to allow for direct comparison. The combination of all monetary values converted from the individual impacts finally represent the overall cost of a proposed design or product.

A noticeable benefit of this approach is placed on eliminating the normalization process involving factor-weighing on each criterion.

Instead, the combination of three monetary values obtained from different models simplifies the decision-making process and removes the need to make, often, biased assumptions. This process can be repeated with a number of models $(1 \ldots M)$, their results can be directly compared and used to determine the most optimal one.

In order to understand the relationship between the input parameters and the analysis outputs, this framework identifies several conceivable scenarios $(1 \ldots N)$ and carries out sensitivity analysis across them. Comparing the results, optimal decision-making can be accomplished as well as allowing for the observation of general trends and/or patterns of the parametric influences on the final decision. 


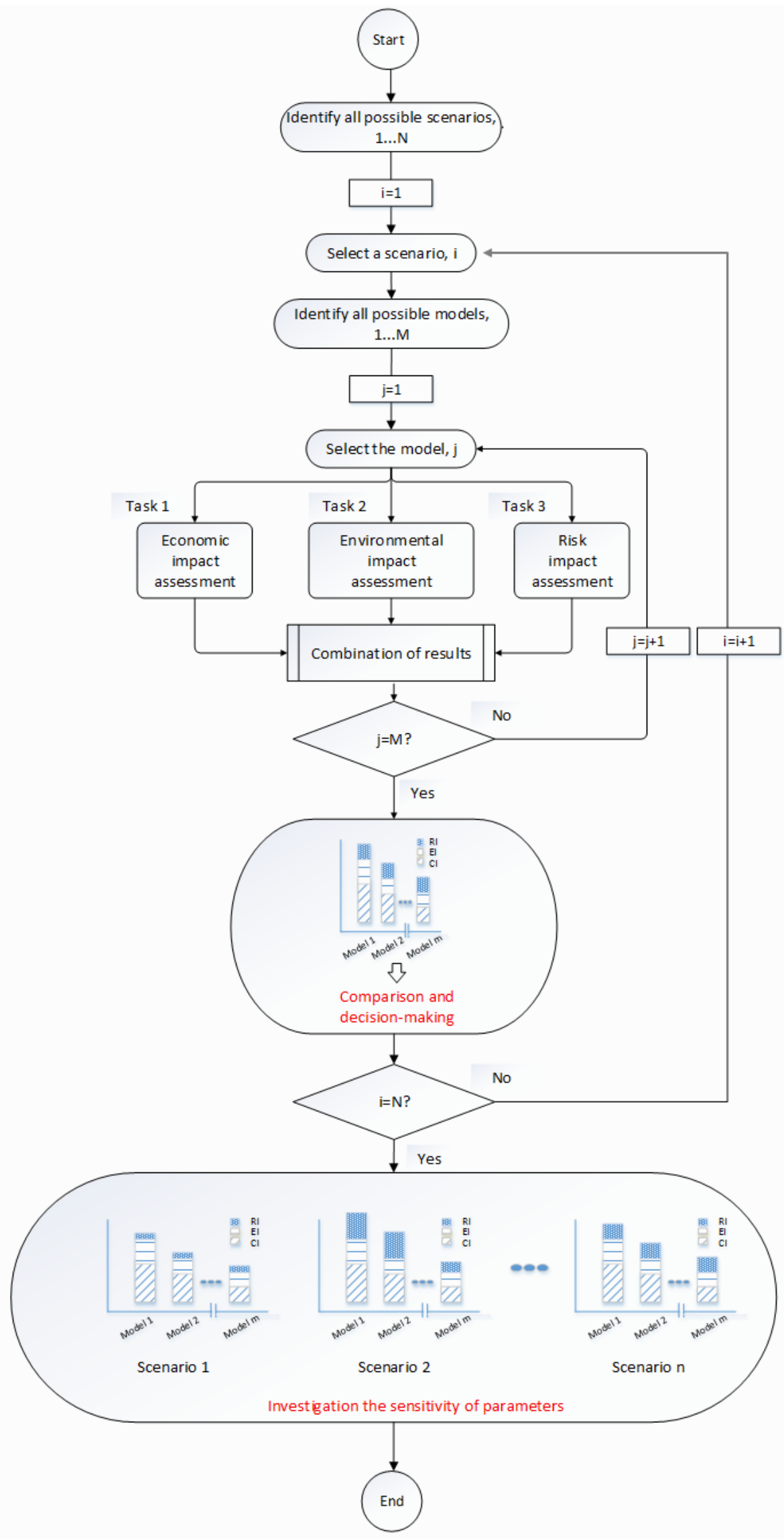

Fig. 1. Schematic of SHIPLYS LCT concept. 


\subsection{Economic impact assessment}

Fig. 2 illustrates the process of economic impact assessment (Task 1) tailored to the scope of the present research. It starts with data collection with which the energy consumption of subject models is estimated. It, then, moves into the process of cost estimation where Eq. (1) is used to calculate the energy expenses.

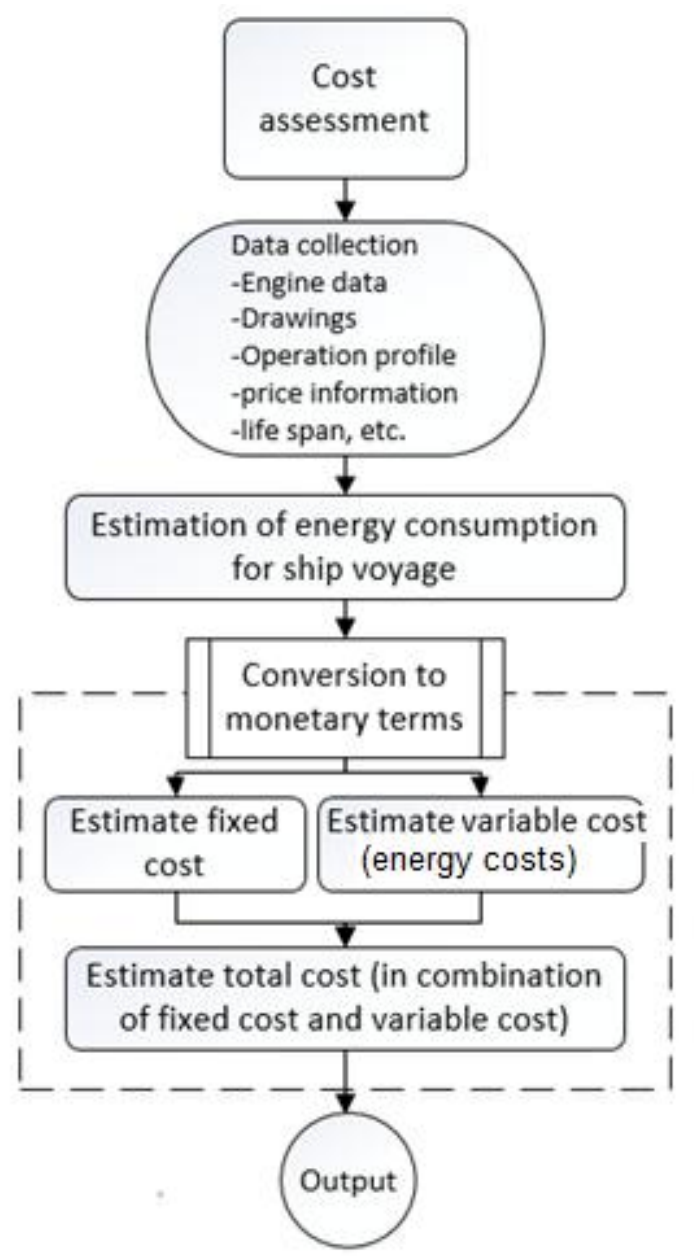

Fig. 2. Outlines for Task 1 - economic impact assessment (estimating variable cost). 


$$
\mathrm{C}_{\mathrm{E}}=\sum_{\mathrm{i}=0}^{\mathrm{n}}\left(\mathrm{SFOC}_{\mathrm{i}} \times \mathrm{FC}_{\mathrm{i}} \times \mathrm{FP} \times \mathrm{SM}+\mathrm{EC}_{\mathrm{i}} \times \mathrm{EP} \times \mathrm{EM}\right) \times \mathrm{t}_{\mathrm{i}}
$$

Given that the holistic cost of a ship is comprised of various costs during the life cycle of the ship, this paper has split the overall ship cost into two types; one is 'fixed cost' that is insensitive to the change in subject models while the other is 'variable cost' which is sensitive to model changes. Focusing on comparing the performance of a ship with a hybrid propulsion system as well as the same ship with two other conventional propulsion types, the category of variable cost, in this paper, can be defined as the capital and operational costs in respect to various propulsion systems, whereas all the other ship costs can be considered as the fixed cost. Finally, the economic impact of the proposed systems can be expressed as the combination of all fixed and variable costs as shown in Eq. (2).

$$
\mathrm{C}_{\mathrm{EC}}=\sum_{\mathrm{i}=0}^{\mathrm{n}} \mathrm{C}_{\mathrm{F}, \mathrm{i}} \times \sum_{\mathrm{j}=0}^{\mathrm{m}} \mathrm{C}_{\mathrm{V}, \mathrm{j}}
$$

\subsection{Environmental impact assessment}

Fig. 3 shows the process of Task 2, which concerns the environmental impact assessment. Considering that marine vessels have been attributed to a number of environmental impacts such as global warming, acidification, eutrophication, etc. Task 2 was designed to investigate the variation of environmental impact obtained from the different configurations of the propulsion systems: hybrid, DE and DM. Similar to Task 1, it begins with the collecting data on emission types, quantities and social costs. 


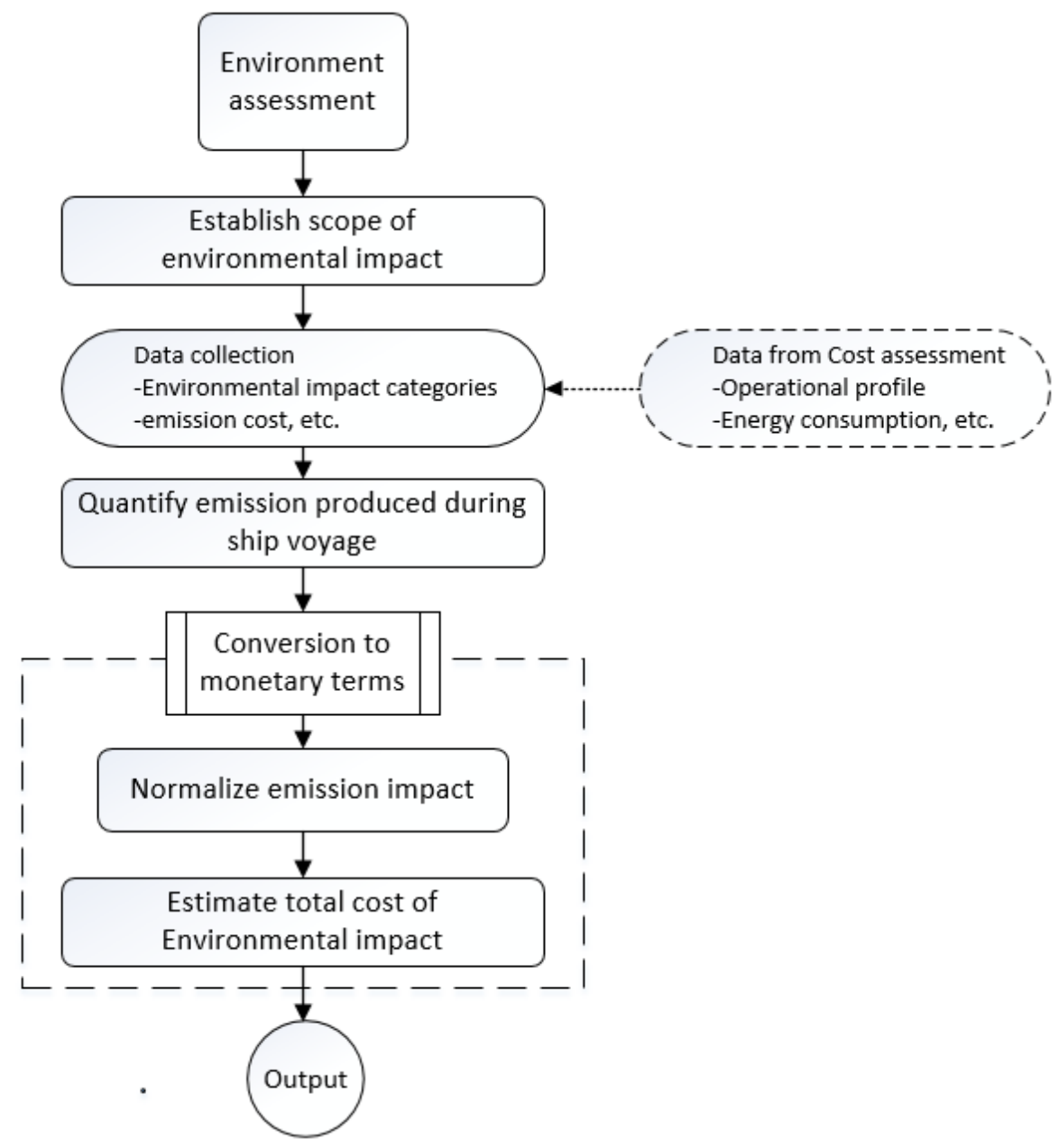

Fig. 3. Outlines for Task 2 - environment impact assessment.

As shown in Table 1, this process quantifies air emissions by means of an international guideline [48] of pollution factors associated with eight major emissions which are generally produced from the exhaust gas of diesel engines in accordance with fuel types.

Table 1 Emission factors for top-down emissions from combustion of fuels [48].

\begin{tabular}{|c|c|c|}
\hline Emissions substance & GWP $\left(\mathrm{tCO}_{2} \mathrm{e}\right)$ & Marine MGO emissions factor $(\mathrm{g} / \mathrm{g}$ fuel $)$ \\
\hline $\mathrm{CO}_{2}$ & 1 & 3.20600 \\
\hline $\mathrm{CH}_{4}$ & 25 & 0.00006 \\
\hline $\mathrm{N}_{2} \mathrm{O}$ & 265 & 0.00015 \\
\hline $\mathrm{NO}_{\mathrm{x}}$ & $\times$ & 0.08725 \\
\hline $\mathrm{CO}$ & 0.027 & 0.00277 \\
\hline
\end{tabular}




\begin{tabular}{|c|c|c|}
\hline NMVOC & $\times$ & 0.00308 \\
\hline $\mathrm{SO}_{\mathrm{x}}$ & $\times$ & 0.00264 \\
\hline $\mathrm{PM}_{25}$ & $\times$ & 0.00102 \\
\hline
\end{tabular}

EU emission reports [49-51] where 29 EU countries evaluated the practical costs of maritime emissions, such as $\mathrm{CO}_{2}, \mathrm{NO}_{\mathrm{x}}, \mathrm{SO}_{\mathrm{x}}$, NMVOC (non-methane volatile organic compound) and $\mathrm{PM}_{2.5}$ (particulate matters from exhaust), were referred to the cost estimation of those emissions.

The quantities of $\mathrm{CO}_{2}, \mathrm{CH}_{4}, \mathrm{CO}$ and $\mathrm{N}_{2} \mathrm{O}$ are represented the degree of global warming potential (GWP) which can be calculated by using Eq. (3).

$$
\mathrm{EI}_{\mathrm{GWP}}=\sum_{\mathrm{i}=1}^{\mathrm{n}} \sum_{\mathrm{j}=1}^{\mathrm{m}} \mathrm{FC}_{\mathrm{i}} \times\left(\mathrm{EF}_{\mathrm{j}} \times \mathrm{GWP}_{\mathrm{j}}\right)
$$

The Environmental impact for other types of emissions are integrated in the same way as shown in Eq. (4).

$$
\mathrm{EI}_{\mathrm{k}}=\sum_{\mathrm{i}=1}^{\mathrm{n}} \sum_{\mathrm{j}=1}^{m} \mathrm{FC}_{\mathrm{i}} \times\left(\mathrm{EF}_{j} \times \mathrm{EIF}_{j, k}\right)
$$

Hence, using Eq. (5), the environmental impacts, expressed as the combination of various emission types and quantities, can be converted into monetary values.

$$
\mathrm{C}_{\mathrm{EI}}=\mathrm{C}_{\mathrm{GWP}} \times \mathrm{EI}_{\mathrm{GWP}}+\sum_{\mathrm{k}=1}^{1} \mathrm{C}_{\mathrm{k}} \times \mathrm{EI}_{\mathrm{k}}
$$

\subsection{Risk impact assessment}

Fig. 4 shows an overview of the proposed risk assessment which can be divided into two steps: 1) risk assessment 2) conversion of results into monetary value. 
This process was structured primarily based on an approach of qualitative risk assessment by using failure mode effect criticality assessment (FMECA) with which the failure modes of a mechanical or electrical system are comprehensively identified. The frequencies, consequences and mitigation measures for individually-identified hazards throughout the FMECA are assessed using a combination of subjective and objective information. This modified process of risk assessment is, then, integrated with decision-making process.

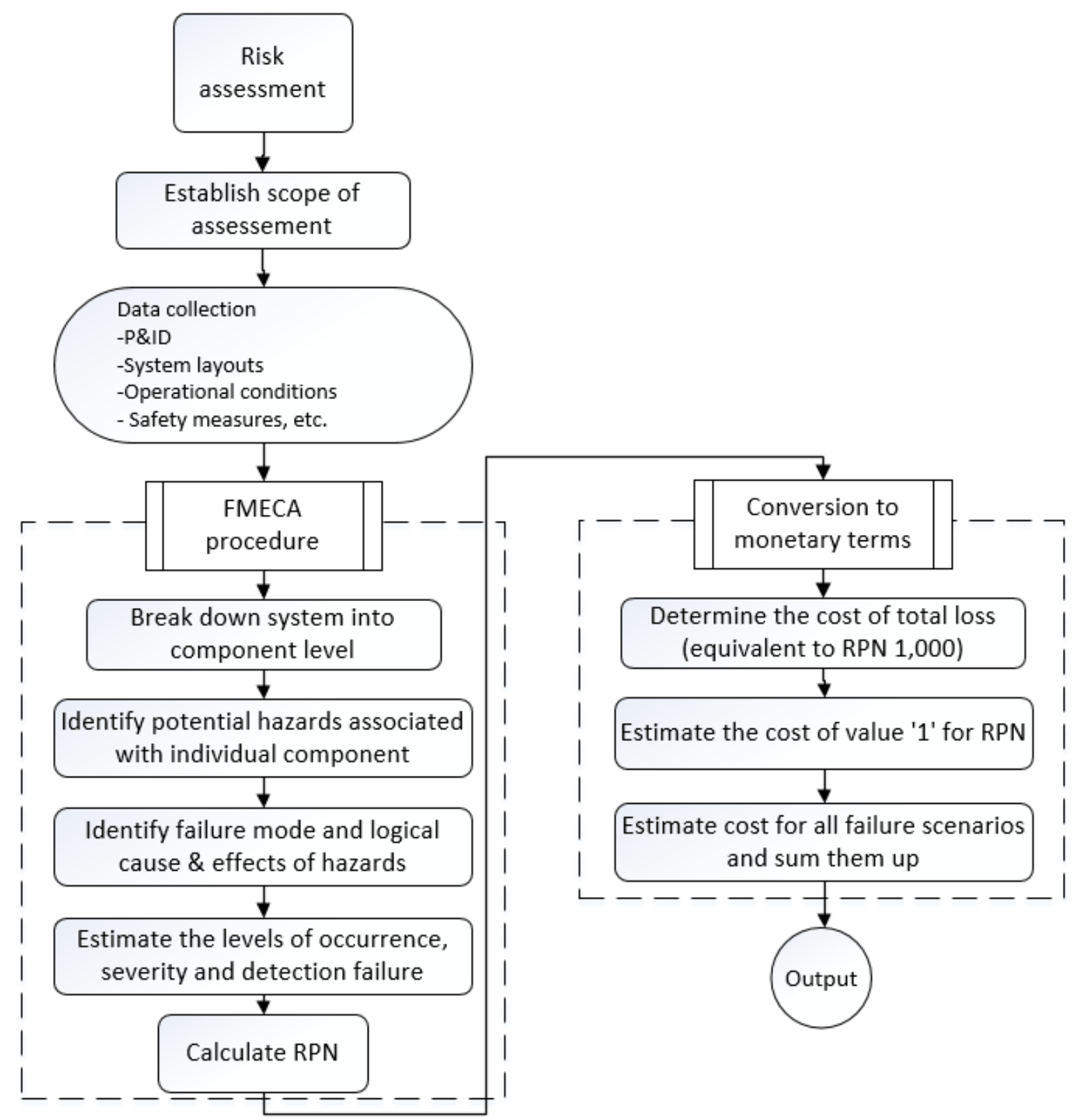

Fig. 4. Outlines for Task 3 - risk impact assessment. 


\subsubsection{Risk assessment}

The first step of risk assessment is to identify potential hazards (equivalent to failure modes of subject systems), which is followed by the assessment of the risk levels of the identified hazards based on three standard risk indexes.

- Occurrence $(\mathrm{O})$ represents the probability of a hazard;

- Severity (S) serves as the consequence of a hazard;

- Mitigation (M) serves as the chance of the failure of detection before a hazard arise or the failure of the coverage by backup systems.

The product of those indexes provides the risk level which is known as the risk priority number (RPN). Table 2 to Table 4 show the different scales used to measure $\mathrm{O}, \mathrm{S}$ and $\mathrm{M}$. Therefore, the RPN can be translated from the combination of O, S, and, D as shown in Eq. (6).

$\mathrm{RPN}=\mathrm{O} \times \mathrm{S} \times \mathrm{D}$

Table 2 Frequency scales [52].

\begin{tabular}{|l|l|l|l|}
\hline Rank & Probability of failures & Human error occurrence Probability & Linguistic Variable \\
\hline 1 & $<1: 20000$ & < every 5 years & Unlikely \\
\hline 2 & $1: 20000$ & In 3-5 years & Low FR \\
\hline 3 & $1: 10000$ & In 1-3 years & \multirow{2}{*}{ Occasional F } \\
\hline 4 & $1: 2000$ & Per year & \\
\hline 5 & $1: 1000$ & In every 6 months & \\
\hline 6 & $1: 200$ & In every 3 months & Repeated F \\
\hline 7 & $1: 100$ & Per months & Inevitable \\
\hline 8 & $1: 20$ & Per week & \\
\hline 9 & $1: 10$ & Every few days & \\
\hline
\end{tabular}




\begin{tabular}{|l|l|l|l|}
\hline 10 & $1: 2$ & Per day & \\
\hline
\end{tabular}

Table 3 Consequence scale [52].

\begin{tabular}{|c|c|c|}
\hline Severity of each effect of failure or error & Effect & Rank \\
\hline No reason to expect failure to have any effect on safety, health, environment or mission & None & 1 \\
\hline $\begin{array}{l}\text { Very minor effect on product or system performance to have any effect on safety or health. The system does } \\
\text { not require repair. }\end{array}$ & Very minor & 2 \\
\hline $\begin{array}{l}\text { Minor effect on product or system performance to have any effect on safety or health. The system can } \\
\text { require repair. }\end{array}$ & Minor & 3 \\
\hline $\begin{array}{l}\text { Very low effect on system performance. A failure is not serious enough to cause injury, property damage, or } \\
\text { system damage, but can result in unscheduled maintenance or repair. }\end{array}$ & Low & 4 \\
\hline $\begin{array}{l}\text { Moderate effect on system performance. The system requires repair. A failure which may cause moderate } \\
\text { injury, moderate property damage, or moderate system damage which will result in delay or loss of system } \\
\text { availability or mission degradation. } 100 \% \text { of mission may need to be reworked or process delayed. }\end{array}$ & Moderate & 5 \\
\hline $\begin{array}{l}\text { System performance is degraded. Some safety functions may not operate. A failure causes injury, property } \\
\text { damage, or system damage. Some portion of mission is lost. High delaying restoring function. }\end{array}$ & Significant & 6 \\
\hline $\begin{array}{l}\text { System performance is severely affected but functions (reduced level of safety performance). The system } \\
\text { may not operate. Failure does not involve noncompliance with government regulations or standards. }\end{array}$ & Major & 7 \\
\hline $\begin{array}{l}\text { The system is inoperable with loss of primary function. Failure can involve hazardous outcomes and/or } \\
\text { noncompliance with government regulations or standards. }\end{array}$ & Extreme & 8 \\
\hline $\begin{array}{l}\text { Failure involves hazardous outcomes and/or noncompliance with government regulations or standards. } \\
\text { Potential safety, health or environmental issue. Failure will occur with a warning. }\end{array}$ & $\begin{array}{l}\text { Very } \\
\text { extreme }\end{array}$ & 9 \\
\hline $\begin{array}{l}\text { Failure is hazardous and occurs without warning. It affects safe operation. A failure is serious enough to } \\
\text { cause injury, property damage, or system damage. Failure will occur without warning. }\end{array}$ & Serious & 10 \\
\hline
\end{tabular}

Table 4 Mitigation scale [52].

\begin{tabular}{|c|c|c|c|}
\hline Likelihood of detection of failure or error & $\begin{array}{l}\text { Degree of } \\
\text { importance }\end{array}$ & $\begin{array}{c}\text { Probability of } \\
\text { failure } \\
\text { detection \% }\end{array}$ & Rank \\
\hline $\begin{array}{l}\text { Current control(s) almost certainly will detect a potential failure mode/task error. } \\
\text { Reliable controls are known with a similar process. }\end{array}$ & Almost certain & $0-5$ & 1 \\
\hline $\begin{array}{l}\text { Very likely current control(s) will detect failure modes/task error. Controls are able to } \\
\text { detect within the same machine/module (almost always preceded by a warning). }\end{array}$ & Very high & $5-15$ & 2 \\
\hline $\begin{array}{l}\text { High chance the design control(s) will almost certainly detect a potential failure } \\
\text { Mode/task error. Controls are able to detect within the same function area. }\end{array}$ & High & $15-25$ & 3 \\
\hline
\end{tabular}




\begin{tabular}{|l|l|l|l|}
\hline Moderately high likelihood current control(s) will detect failure modes/task error. & Moderately high & $25-35$ \\
\hline $\begin{array}{l}\text { Moderate chance that the design control will detect a potential failure mode/task } \\
\text { or the defect will remain undetected until the system performance is affected. }\end{array}$ & Moderately & $35-45$ & 5 \\
\hline $\begin{array}{l}\text { Low likelihood current control(s) will detect failure modes/task error (program or } \\
\text { operator is not likely to detect a potential design weakness). }\end{array}$ & Low & $45-55$ & 6 \\
\hline $\begin{array}{l}\text { Very low likelihood current control(s) will detect failure modes/task error (program } \\
\text { or }\end{array}$ & Very low & $55-65$ & 7 \\
$\begin{array}{l}\text { Operator will not to detect a potential design weakness). } \\
\text { Remote chance that the design control will detect a potential failure mode/task error, } \\
\text { Or the defect will remain undetected until an inspection or test is carried out. }\end{array}$ & Remote & $75-85$ \\
\hline $\begin{array}{l}\text { Defect most likely remains undetected (very remote chance that the design control } \\
\text { will } \\
\text { detect a potential cause/mechanism and subsequent failure modes) or the task will be } \\
\text { performed in the presence of the defect }\end{array}$ & Very remote & $85-95$ \\
\hline $\begin{array}{l}\text { System failures are not detected (design control will not and/or cannot detect a } \\
\text { potential cause/mechanism and subsequent failure modes) or there is no design } \\
\text { verification or the task will certainly be performed in the presence of the defect. }\end{array}$ & impossible & $80-100$ \\
\hline
\end{tabular}

\subsubsection{Conversion into monetary values}

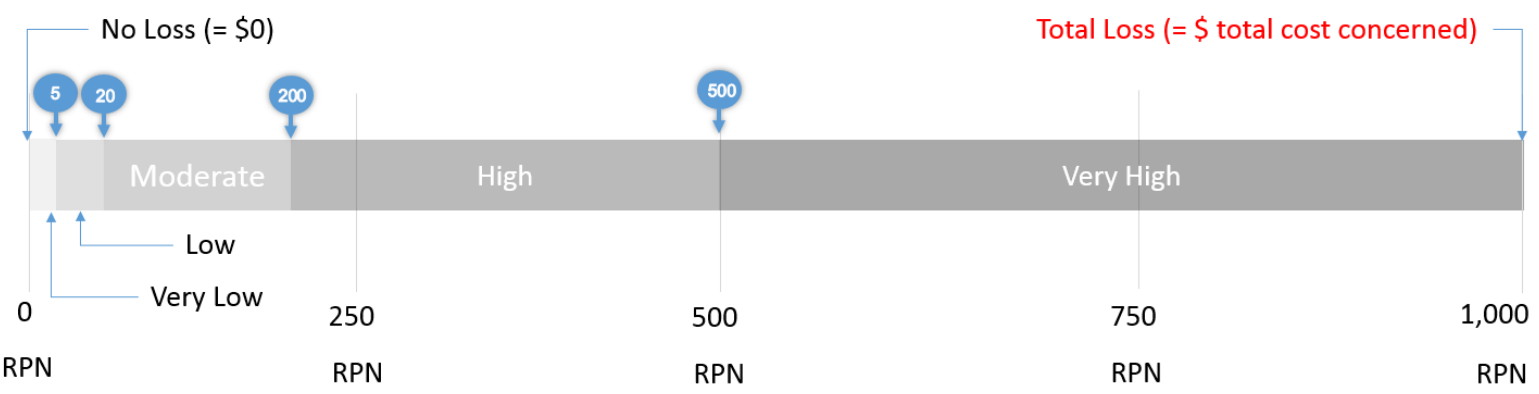

Fig. 5. Principle for cost estimation in accordance with RPN.

Fig. 5 illustrates the principle for converting the RPN into monetary value. The RPN is technically ranked between 1 and 1,000. In the proposed process, the RPN 1,000 is assumed to represent the worst accident case which may be equivalent to the total loss of the ship. 
Hence, the cost value of the RPN 1,000 equals the total cost of the ship. With this theory, the unit value of RPN ' 1 ' can be determined if the cost of RPN 1,000 is divided by 1,000. For example, if the cost of the total loss is $\$ 1$ million equivalent to RPN 1,000, the value of RPN ' 1 ' turns out $\$ 1,000$. Using Eq. (7), the risk impact can be converted into monetary value.

$$
\mathrm{C}_{\mathrm{RI}}=\sum_{\mathrm{h}=1}^{\mathrm{O}}\left(\mathrm{RPN}_{\mathrm{h}} \times \mathrm{C}_{\mathrm{RPN}}\right)
$$

\subsection{Optimal decision-making}

The overall costs for economic, environmental and risk impacts of the proposed system models are presented by means of Eq. (8). Different models and scenarios may result in different total costs. The optimal decision-making can be achieved by comparing those total costs across the concerned scenarios and models, thereby determining the model and scenario with the lowest total cost. As shown in Fig. 1, this process can be simply conducted with bar graphs where the staked costs associated with each impact represent the total costs of each model and scenario.

$$
\mathrm{C}_{\mathrm{T}}=\mathrm{C}_{\mathrm{EC}}+\mathrm{C}_{\mathrm{EV}}+\mathrm{C}_{\mathrm{RI}}
$$




\section{Case study}

\subsection{Selection of three system models $(1 \ldots M=3)$}

The selected hybrid ro-ro ferry, MV Catriona, has been engaged in the coastal service between the route of Claonaig - Lochranza, Scotland, UK since its initial delivery in September 2016. It was equipped with two lithium-ion batteries (350 kW each) and integrated with the diesel electric propulsion systems. Basic details of the ship are summarized in Table 5.

Table 5 General characteristics of MV Catriona [3].

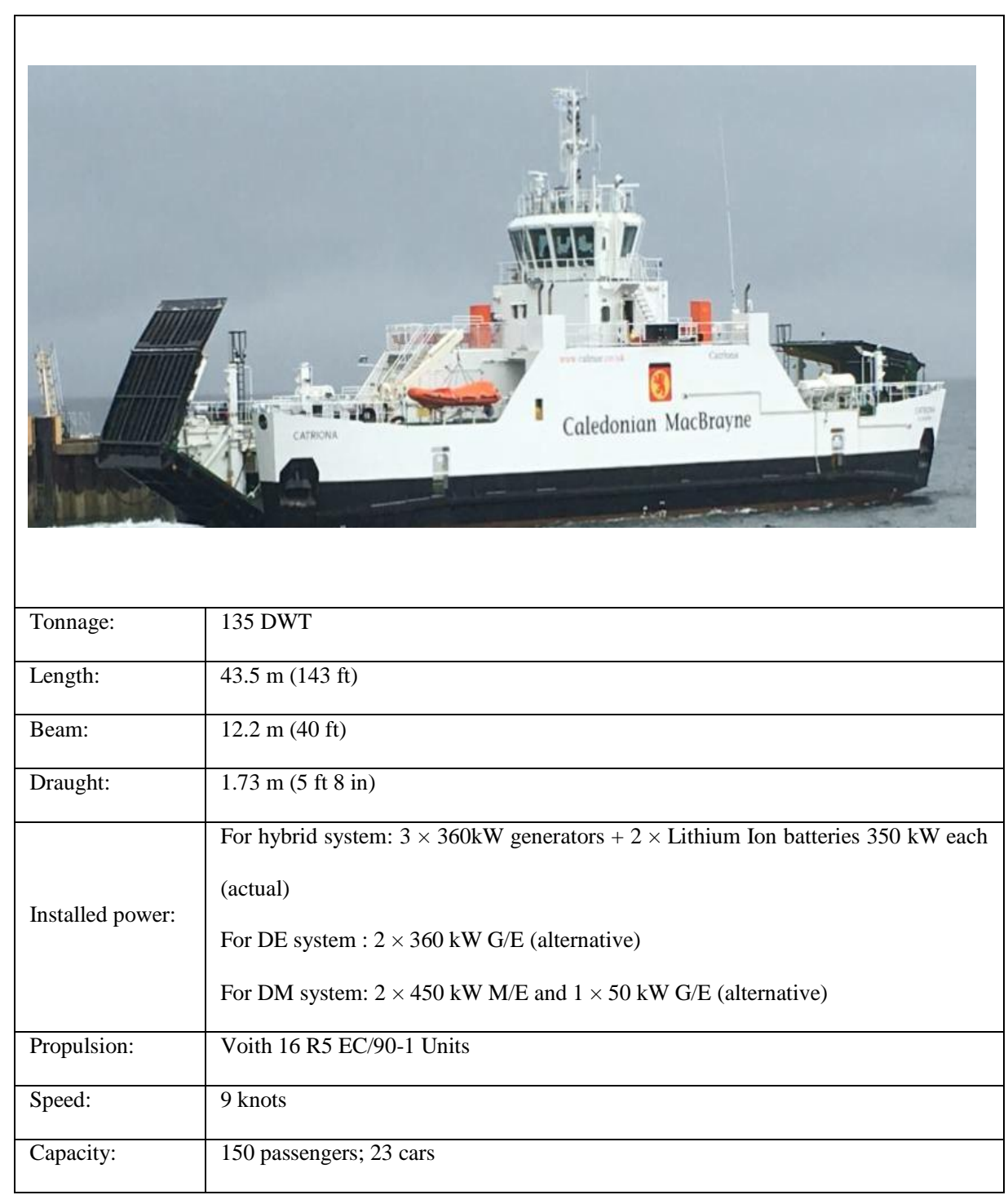




\begin{tabular}{|l|l|}
\hline Route: & Claonaig - Lochranza, UK \\
\hline Fuel type & Marine gas oil (MGO) \\
\hline
\end{tabular}

Having the hybrid concept, the case ship was designed to be operated either by electricity from diesel driven generators or lithium-ion batteries. It could also utilize both power sources simultaneously. In short, the case ship runs in three variant modes: the diesel mode, the battery mode and the hybrid mode.

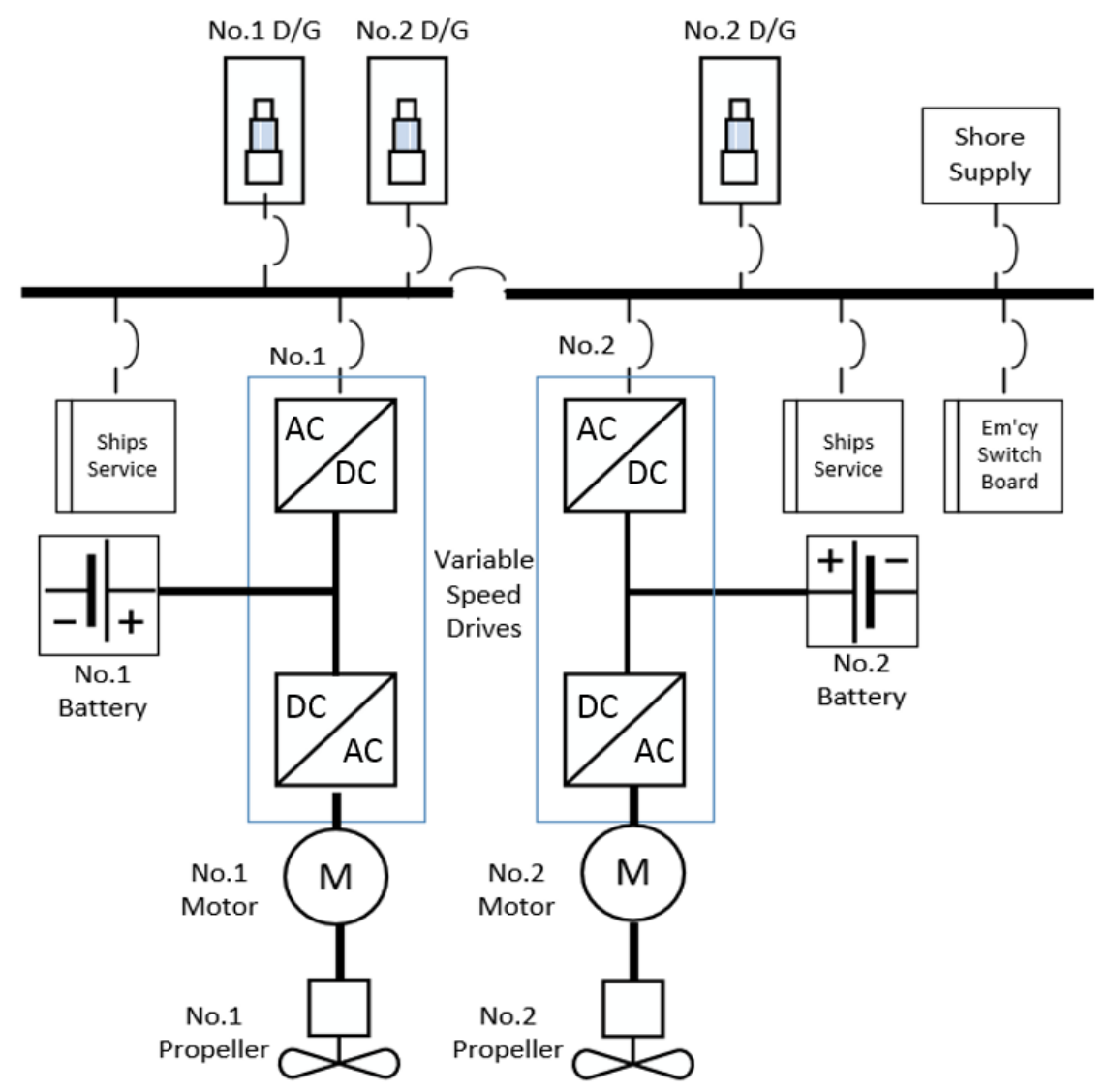

Fig. 6. Drawing for MV Catrina (System model 1) [3].

Fig. 6 shows a diagram of the electrical load distribution for the case ship. In the diesel mode, the electrical power from the diesel generators is transmitted to the main switchboard. The 
Table 6 General characteristics of MV Catriona [3].

\begin{tabular}{|c|c|c|c|c|c|c|c|}
\hline \multirow{2}{*}{\multicolumn{2}{|c|}{$\begin{array}{c}\text { Service route } \\
\text { Operation profile }\end{array}$}} & \multicolumn{6}{|c|}{ Claonaig - Lochranza } \\
\hline & & \multicolumn{2}{|c|}{ Transit } & \multicolumn{2}{|c|}{ Manoeuvring } & \multicolumn{2}{|c|}{ At Slip } \\
\hline \multicolumn{2}{|c|}{ One voyage (minute) } & & 40 & & 4 & & $16-46$ \\
\hline \multicolumn{2}{|c|}{ Average daily voyage (minute) } & \multicolumn{2}{|r|}{360} & \multicolumn{2}{|r|}{36} & \multicolumn{2}{|r|}{224} \\
\hline \multicolumn{2}{|c|}{ Power demand $(\mathrm{kW})$ for hybrid } & \multicolumn{2}{|c|}{322 / 291} & \multicolumn{2}{|c|}{$144 / 130$} & \multicolumn{2}{|c|}{$87 / 78$} \\
\hline System & Propulsion type & \multicolumn{6}{|c|}{ Operational practice } \\
\hline \multirow[t]{2}{*}{1} & $\begin{array}{c}\text { Hybrid } \\
\text { (current practice) }\end{array}$ & $72 \%$ & $\begin{array}{c}1 \mathrm{G} / \mathrm{E}+2 \\
\text { batteries } \\
(20 \%)\end{array}$ & $40 \%$ & $1 \mathrm{G} / \mathrm{E}$ & $24 \%$ & $1 \mathrm{G} / \mathrm{E}$ \\
\hline & Hybrid (optional) & $45 \%$ & $2 \mathrm{G} / \mathrm{E}$ & $0 \%$ & 2 batteries & $0 \%$ & 2 batteries \\
\hline 2 & $\mathrm{DE}$ & $45 \%$ & $2 \mathrm{G} / \mathrm{E}$ & $40 \%$ & $1 \mathrm{G} / \mathrm{E}$ & $24 \%$ & $1 \mathrm{G} / \mathrm{E}$ \\
\hline 3 & $\mathrm{DM}$ & $32 \%$ & $2 \mathrm{M} / \mathrm{E}+1$ & $14 \%$ & $2 \mathrm{M} / \mathrm{E}$ & $9 \%$ & $2 \mathrm{M} / \mathrm{E}$ \\
\hline
\end{tabular}

power is distributed where needed; in particular, it is mainly used to drive the propulsion motors via variable speed drives. In the battery mode, the on-board batteries substitute the role of the diesel generators as the electric energy stored in the batteries is directly supplied to the variable speed drives.

In the hybrid mode, both the battery and the diesel generator systems are connected together to supply the propulsion power in order to share the propulsion loads.

Based on the proposed voyage and associated engine loads described in Table 6 , the energy consumption of the case ship was estimated. In the table, the proposed power loads for the alternative ships with DE and DM systems were also described. 


\begin{tabular}{|l|l|l|l|l|l|l|l|}
\hline & & & $\mathrm{G} / \mathrm{E}$ & & $+1 \mathrm{G} / \mathrm{E}$ & & $+1 \mathrm{G} / \mathrm{E}$ \\
\hline
\end{tabular}

Since the working load of diesel engines is unlikely to exceed the $75 \%$ of the total load for safety reasons, it was found that the hybrid ships could take an advantage from running a single engine during transit, while the DE ship required two generators during the same period. As well as two main generators for propulsion, the ship with the DM required an additional generator to cover electrical service loads.

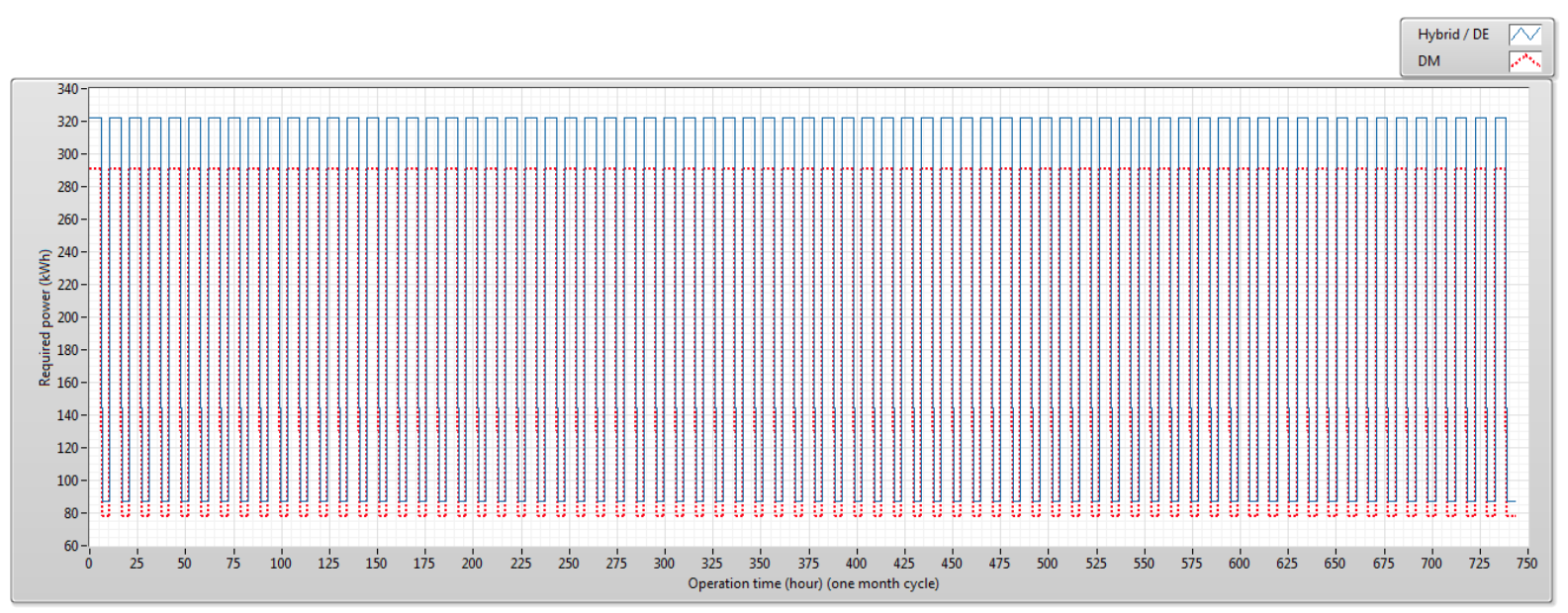

Fig. 7. Estimated ship load profile in the proposed voyage (for one-month operation).

Fig. 7 shows the estimation of shipload profile in the planned voyage (for the six-month operation), with which the energy consumptions were estimated. To investigate the adequacy of this estimation, the calculation results were compared with the actual on-board records of energy consumption. Fig. 8 plots the daily energy consumption of MV Catriona during the six month period between October 2016 and March 2017. 

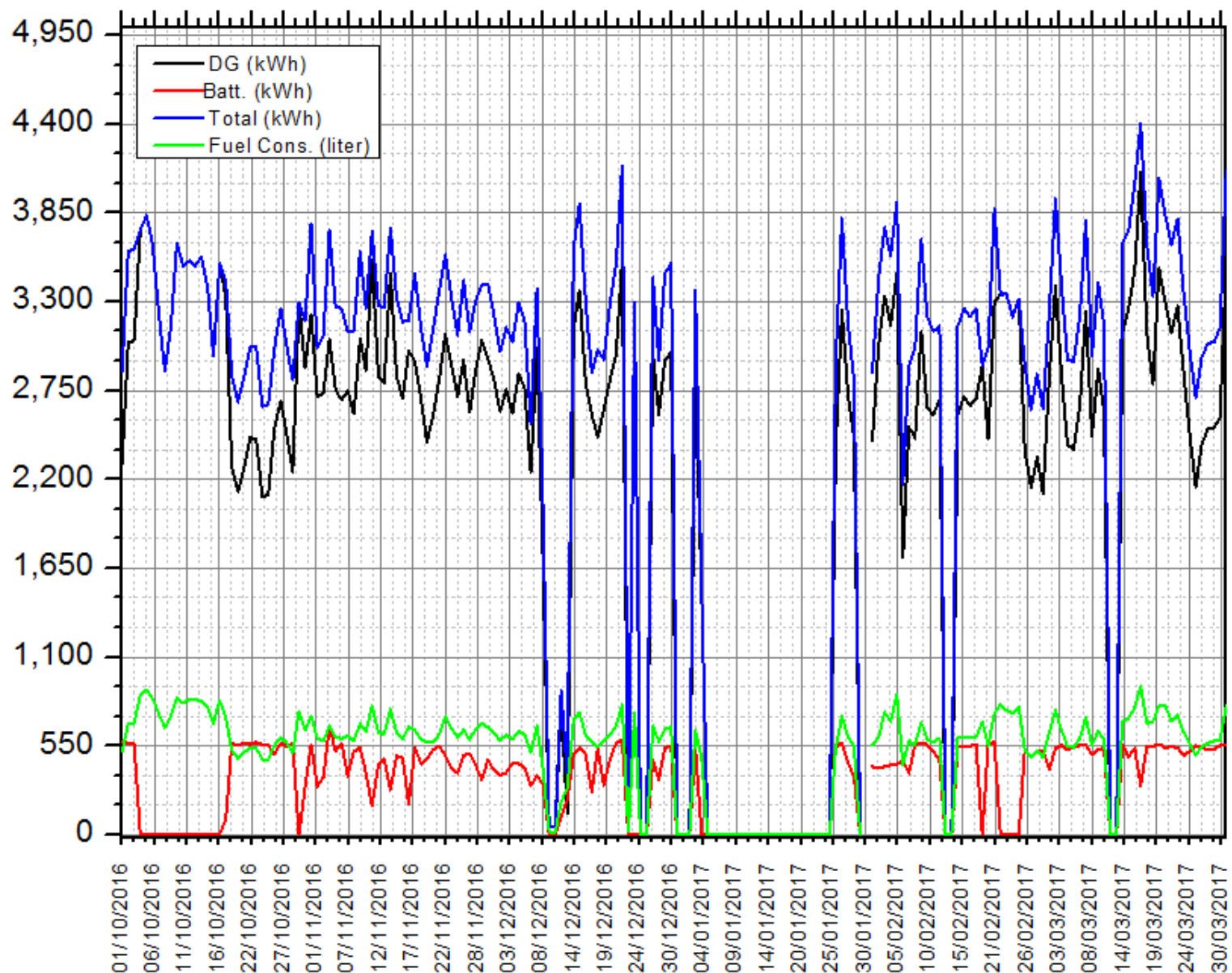

Fig. 8. Daily energy consumption of MV Catriona.

It was found that the ship operators normally used the hybrid mode during daily operations; the batteries supplied of $20 \%$ of the total ship demand while the diesel generators accounted for the remainder. The on-board batteries were re-charged overnight for a period of 11 hours from the shore supply. 


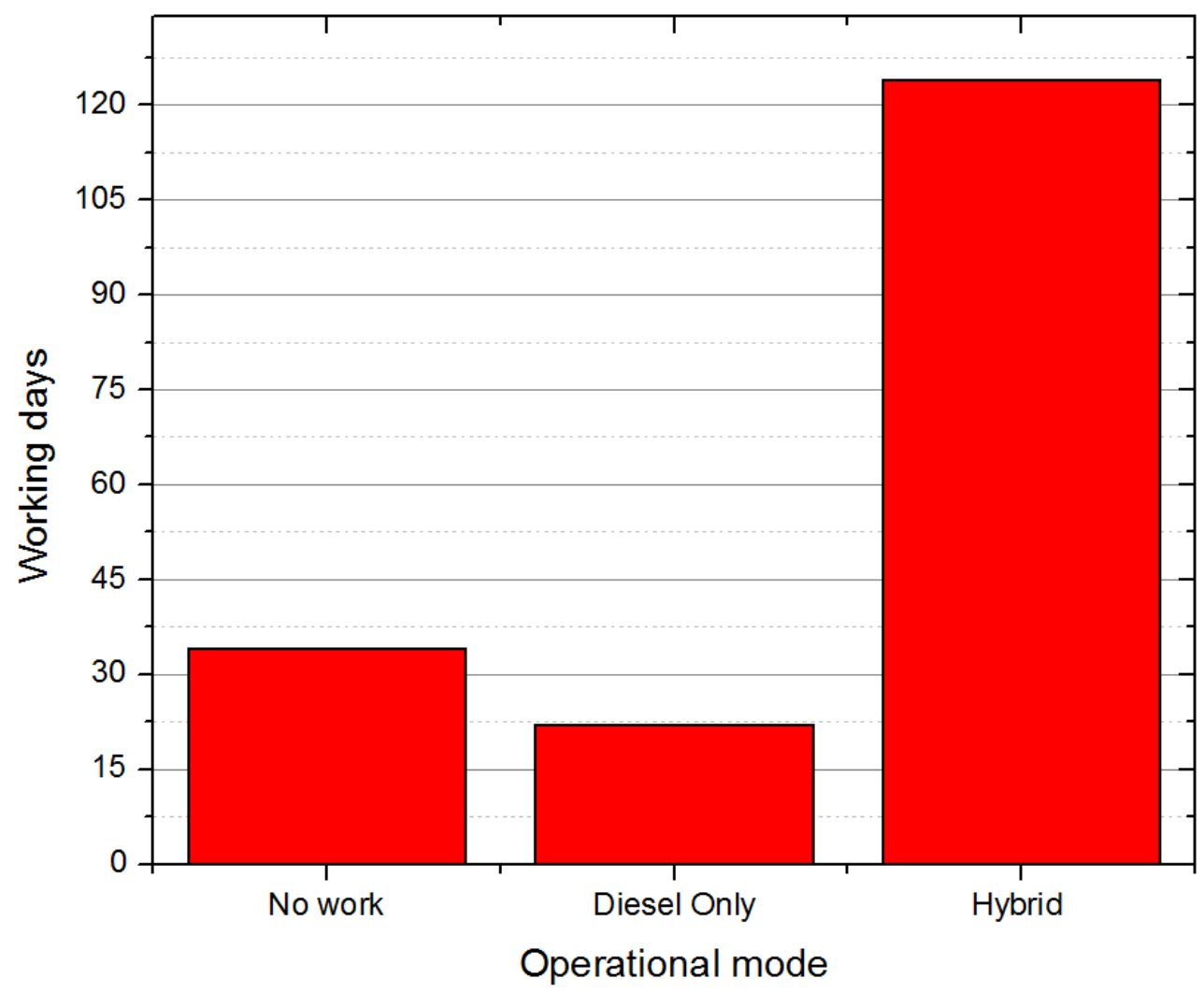

Fig. 9. Operational mode for six-month operation.

In Fig. 9, although the hybrid operation was routinely, the diesel mode was occasionally used particularly during bad weather. Some voyage schedules had to be cancelled due to adverse weather conditions or maintenance purposes. Given this operational data, the case ship was assumed to be operated 313 days in a year.

The fuel consumption was measured as 95,123 litres and the battery consumption was 60,170 kWh during six months of normal operation. The fuel consumption calculated from the analytical model based on Eq. (1) was 91,042 litres (97.0\% of the actual record) and the battery consumption was $57,500 \mathrm{kWh}(95.5 \%$ of the actual record). Therefore, it can be perceived that disparity level between the actual record and analytical calculation is small. 


\subsection{Selection of three operational scenarios $(1 \ldots N=3)$}

The case ship has been in regular use since its delivery. However, it is possible that the routes and the operational conditions will change in the future, which will have an influence on energy consumption.

\subsubsection{Current operational practice (Scenario 1)}

The first scenario was set up on the basis of the actual operating practice in order to compare the performance of the hybrid ship with those of the DE and DM ships. The assumptions used are outlined below.

- Marine gas oil (MGO) was used for operating diesel engines and the fuel cost was \$ 479.5 per metric tonne (assessed on $6^{\text {th }}$ Sep. 2017 [53]).

- Electricity cost was $\$ 0.08 / \mathrm{kWh}$ at night time charge [54].

- UK-based environmental impact costs: GWP for \$24/tCO2e, $\mathrm{NO}_{\mathrm{x}}$ for $\$ 4,602 /$ tonne, $\mathrm{SO}_{\mathrm{x}}$ for $\$ 7,788 /$ tonne, $\mathrm{PM}_{25}$ for $\$ 71,626 /$ tonne, and NMVOC for $\$ 1,298 /$ tonne.

- Costs of total loss (equivalent to RPN 1000) were $\$ 12,187,000$ for the hybrid, $\$$ $12,014,940$ for the DE and $\$ 12,000,000$ for the DM.

Engine maintenance intervals, replaceable items, and associated costs were estimated in accordance with the manufacture's information (MAN Diesel). With regard to this, the engine maintenance costs were evaluated at $\$ 4.4 / \mathrm{h}$ for a $360 \mathrm{~kW}$ engine while $\$ 5.4 / \mathrm{h}$ for a $450 \mathrm{~kW}$ engine and the results were plotted in Fig. 10. 


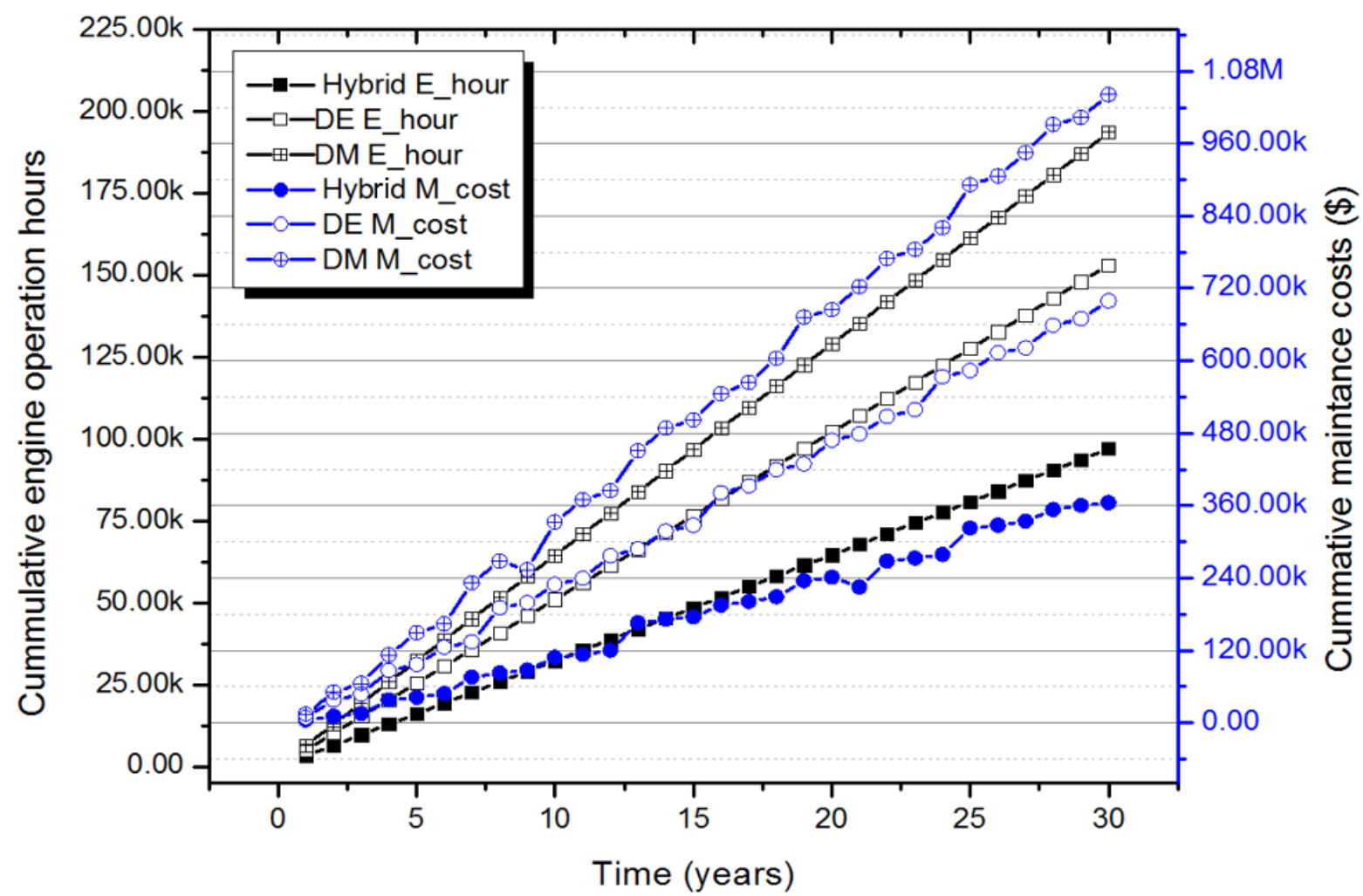

Fig. 10. Engine operation hours vs maintenance costs.

Table 7 compares the economic and environmental impacts across the hybrid, DE and DM systems, showing that hybrid system would be relatively more advantageous in terms of environmental impact than the other two systems. The DE system turned out the most optimistic in terms of the economic impact.

Table 7 Results of economic and environmental impact assessment.

\begin{tabular}{|c|c|c|c|}
\hline & Hybrid & $\mathrm{DE}$ & $\mathrm{DM}$ \\
\hline \multicolumn{4}{|c|}{ Economic impact } \\
\hline Ship price & $\$ 12,215,140.00$ & $\$ 12,014,940.00$ & $\$ 12,000,000.00$ \\
\hline Energy price & $\$ 1,430,984.68$ & $\$ 1,104,531.63$ & $\$ 1,164,972.20$ \\
\hline engine & $\$ 364,988.00$ & $\$ 592,328.00$ & $\$ 882,290.00$ \\
\hline
\end{tabular}




\begin{tabular}{|l|r|r|r|}
\hline maintenance costs & & \\
\hline Total & $\$ 14,011,112.68$ & $\$ 13,711,799.63$ & $\$ 14,047,262.20$ \\
\hline \multicolumn{3}{|c|}{ Environmental impact (life time) } \\
\hline GWP & $\$ 519,446.97$ & $\$ 559,860.51$ & $\$ 590,496.38$ \\
\hline $\mathrm{NO}_{\mathrm{x}}$ & $\$ 2,351,094.65$ & $\$ 2,534,012.37$ & $\$ 2,672,674.89$ \\
\hline $\mathrm{SO}_{\mathrm{x}}$ & $\$ 120,389.31$ & $\$ 129,755.73$ & $\$ 136,856.04$ \\
\hline PM $_{25}$ & $\$ 427,788.33$ & $\$ 461,070.73$ & $\$ 486,300.77$ \\
\hline NMVOC & $\$ 23,409.03$ & $\$ 25,230.28$ & $\$ 26,610.90$ \\
\hline Total & $\$ 3,442,128.30$ & $\$ 3,709,929.62$ & $\$ 3,912,938.97$ \\
\hline
\end{tabular}

The risk impact assessment was carried out with the system drawings as presented through Fig. 6 for the hybrid, Fig. 11 for the DE and Fig. 12 for the DM. Results are displayed in Table 8 to10.

Table 8 Results of risk assessment for Hybrid propulsion system.

\begin{tabular}{|c|c|c|c|c|c|c|c|}
\hline No & Hazard & FI & CI & MI & RPN & Costs & Safety guards \\
\hline 1 & $\begin{array}{l}\text { No.1 Battery bank fails } \\
\text { during normal operation }\end{array}$ & 1 & 2 & 1 & 4 & $\$ 48,860.56$ & $\begin{array}{l}\text { Switch to No.2 Battery bank or Switch to DE mode. } \\
\text { May need to repair the failure part. }\end{array}$ \\
\hline 2 & $\begin{array}{l}\text { No.2 Battery bank fails } \\
\text { during normal operation }\end{array}$ & 1 & 2 & 1 & 4 & $\$ 48,860.56$ & $\begin{array}{l}\text { Switch to No.1 Battery bank or Switch to DE mode. } \\
\text { May need to repair the failure part. }\end{array}$ \\
\hline 3 & $\begin{array}{l}\text { No.1 Motor Fails during } \\
\text { normal operation }\end{array}$ & 2 & 6 & 2 & 24 & $\$ 293,163.36$ & $\begin{array}{l}\text { No. } 2 \text { motor is only used for propulsion. Urgently need } \\
\text { to repair the failure part. }\end{array}$ \\
\hline 4 & $\begin{array}{l}\text { No.2 Motor Fails during } \\
\text { normal operation }\end{array}$ & 2 & 6 & 2 & 24 & $\$ 293,163.36$ & $\begin{array}{l}\text { No. } 1 \text { motor is only used for propulsion. Urgently need } \\
\text { to repair the failure part. }\end{array}$ \\
\hline 5 & $\begin{array}{l}\text { No.1 DC Variable speed } \\
\text { drives fails during normal } \\
\text { operation }\end{array}$ & 1 & 6 & 2 & 12 & $\$ 146,581.68$ & $\begin{array}{l}\text { No. } 2 \text { motor is only used for propulsion (No.1 motor is } \\
\text { out of control) Urgently need to repair the failure part. }\end{array}$ \\
\hline 6 & $\begin{array}{l}\text { No.2 DC Variable speed } \\
\text { drives fails during normal } \\
\text { operation }\end{array}$ & 1 & 6 & 2 & 12 & $\$ 146,581.68$ & $\begin{array}{l}\text { No. } 1 \text { motor is only used for propulsion (No. } 2 \text { motor is } \\
\text { out of control) Urgently need to repair the failure part. }\end{array}$ \\
\hline
\end{tabular}


AFT battery charger fails

$8 \quad$ FWD battery charger fails

To. 1 Gils

9

No.1 G/E fails

No. 2 G/E fails

No.3 G/E fails

Total
$\$ 12,215.14$

$\$ 12,215.14$

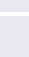

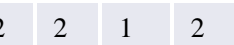

$\$ 24,430.28$

$\$ 24,430.28$

FWD battery charger can be used. May need to repair the failure part.

AFT battery charger can be used. May need to repair the failure part.

No.1 \& 3 G/E can be used. Hybrid can be still useful.

$\$ 24,430.28 \quad$ No. $2 \& 3$ G/E can be used. Hybrid can be still useful.

$\$ 1,074,932.32$

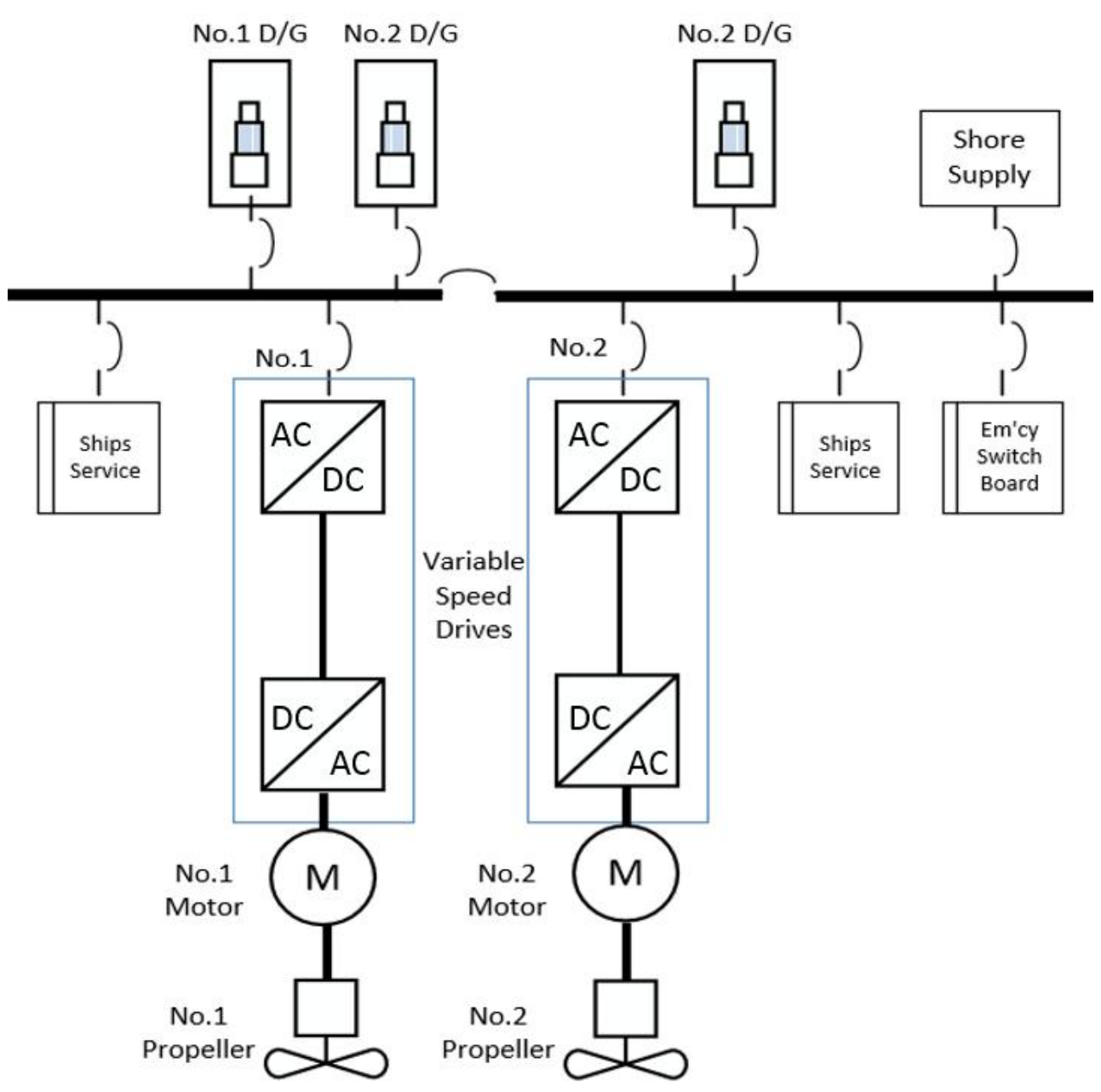

Fig. 11. Drawing for DE propulsion system (System model 2) [3].

Table 9 Results of risk assessment for DE propulsion system. 
4

No.2 DC Variable speed drives fails during normal operation

No.1 G/E fails

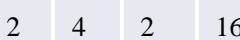

16

No.2 G/E fails

No.3 G/E fails
$\$ 192,239.04$

$\$ 288,358.56$

$\$ 288,358.56$

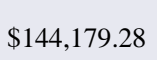

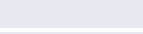
need to be reduced. May need to repair the failure part.

No. 1 \& 3 G/E can be used. Ship speed may $\$ 192,239.04 \quad$ need to be reduced. May need to repair the failure part.

No.1 \& 2 G/E can be used. Ship speed may need to be reduced. May need to repair the failure part.

Urgently need to repair the failure part.

No.1 motor is only used for propulsion.

Urgently need to repair the failure part.

No. 2 motor is only used for propulsion (No.1 motor is out of control) Urgently need to repair the failure part.

No.1 motor is only used for propulsion (No.2 motor is out of control) Urgently need to repair the failure part.

No. 2 \& $3 \mathrm{G} / \mathrm{E}$ can be used. Ship speed may $\$ 192,239.04$

Total

$\$ 1,441,792.80$
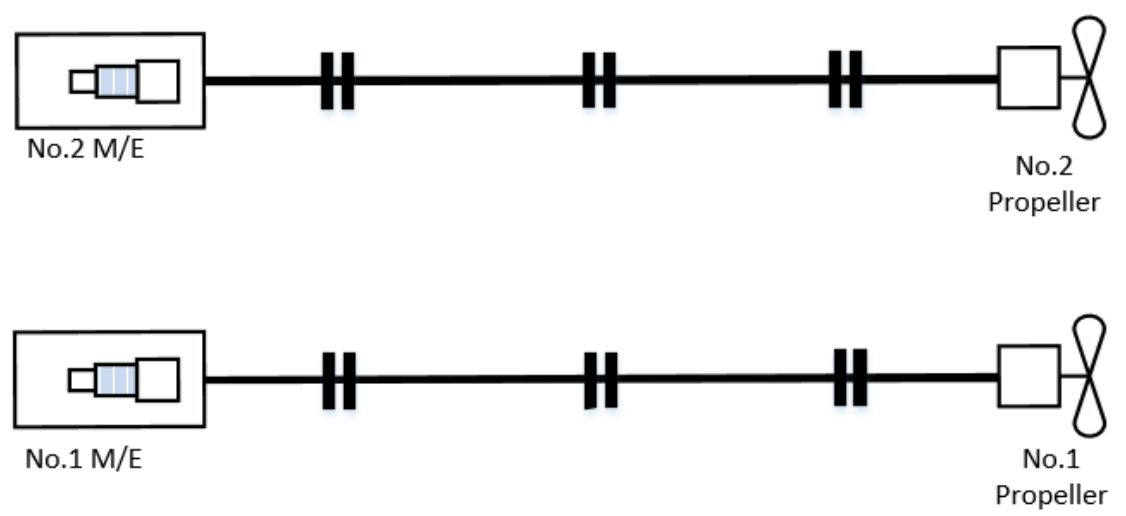

Fig. 12. Drawing for DM propulsion system (System model 3) [3].

Table 10 Results of risk assessment for DM propulsion system.

(n)


For the verification work, the adequacy of the estimated costs in relation to the individual failure mode, expressed as the RPN, was investigated by the operator of the case ship, Caledonian MacBrayne Ltd., the. Judging from their long operational history and estimates of system repair and maintenance, it was agreed that the estimated costs for the individual risks had been placed on reasonably acceptable levels. 


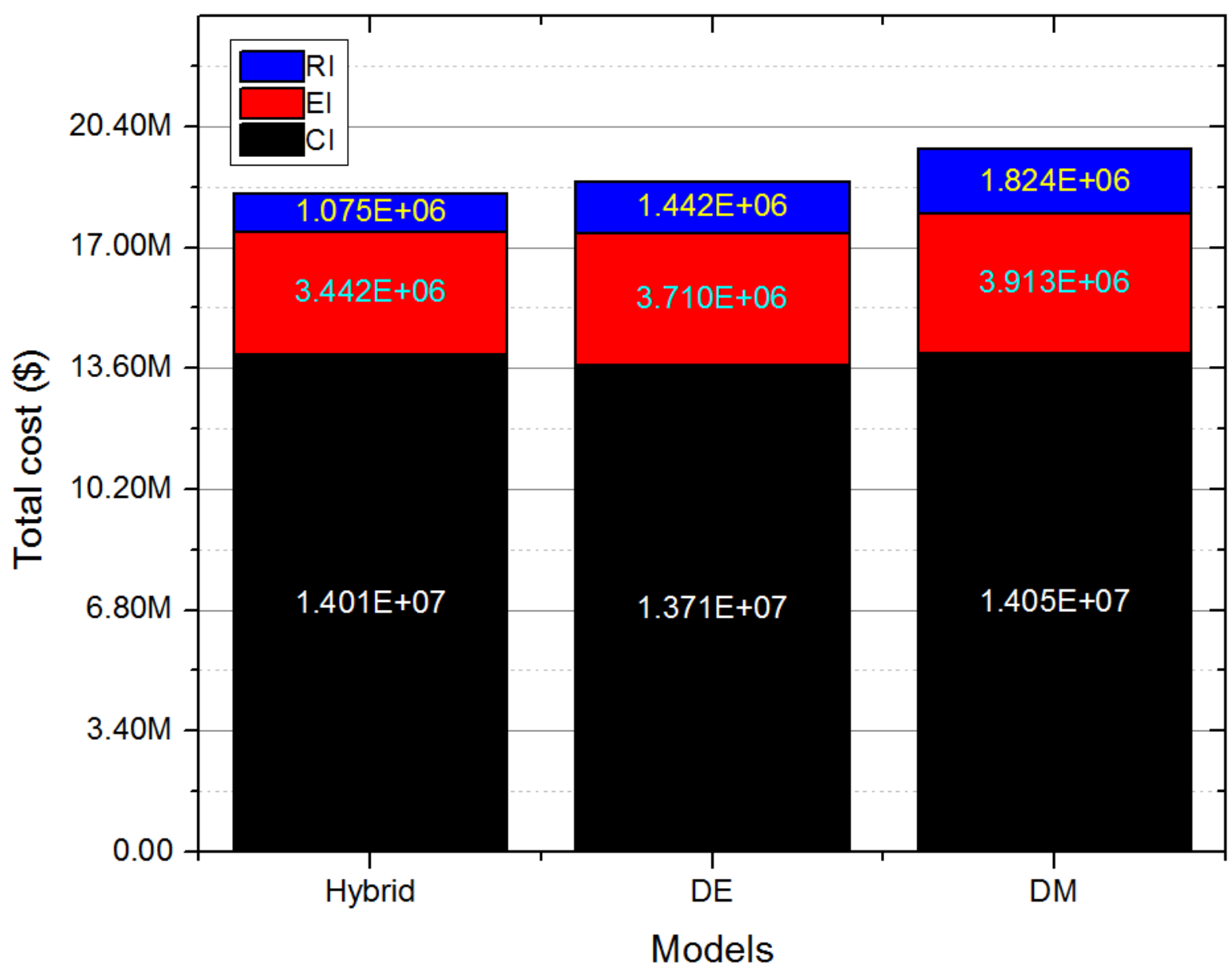

Fig. 13. Analysis results based on initial (actual) scenario.

The overall results for the initial scenario, as shown in Fig. 13, were expressed in monetary values; the hybrid ship was estimated at $\$ 18,163,185.30$, while DE was at $\$ 18,271,194.06$ and DM was at $\$ 18,901,911.17$ respectively.

It was shown that the ship with the hybrid system would be the most desirable option in showing that the total cost of this model was lowest; Despite relatively higher economic impact, the hybrid system outperformed the other two systems overall. In the opposite way, the DM system was shown to be less desirable than the others. 


\subsubsection{Optimization of hybrid mode (Scenario 2)}

As discussed earlier, the current practice of the propulsion load distribution was $80 \%$ for G/Es and $20 \%$ for batteries during the transit mode, while the batteries were switched off during the manoeuvring and berthing modes.

This paper proposed an alternative scenario where the battery mode would be operated during manoeuvring and berthing, while two diesel generators would run in parallel during transit. The difference in results between the initial and alternative scenarios was presented in Fig. 14. It pointed out that the alternatively-proposed scenario regarding the battery usage was slightly better off than the initial practice, revealing that the economic and environmental impacts were, to some extent, reduced by selecting this modified scenario.

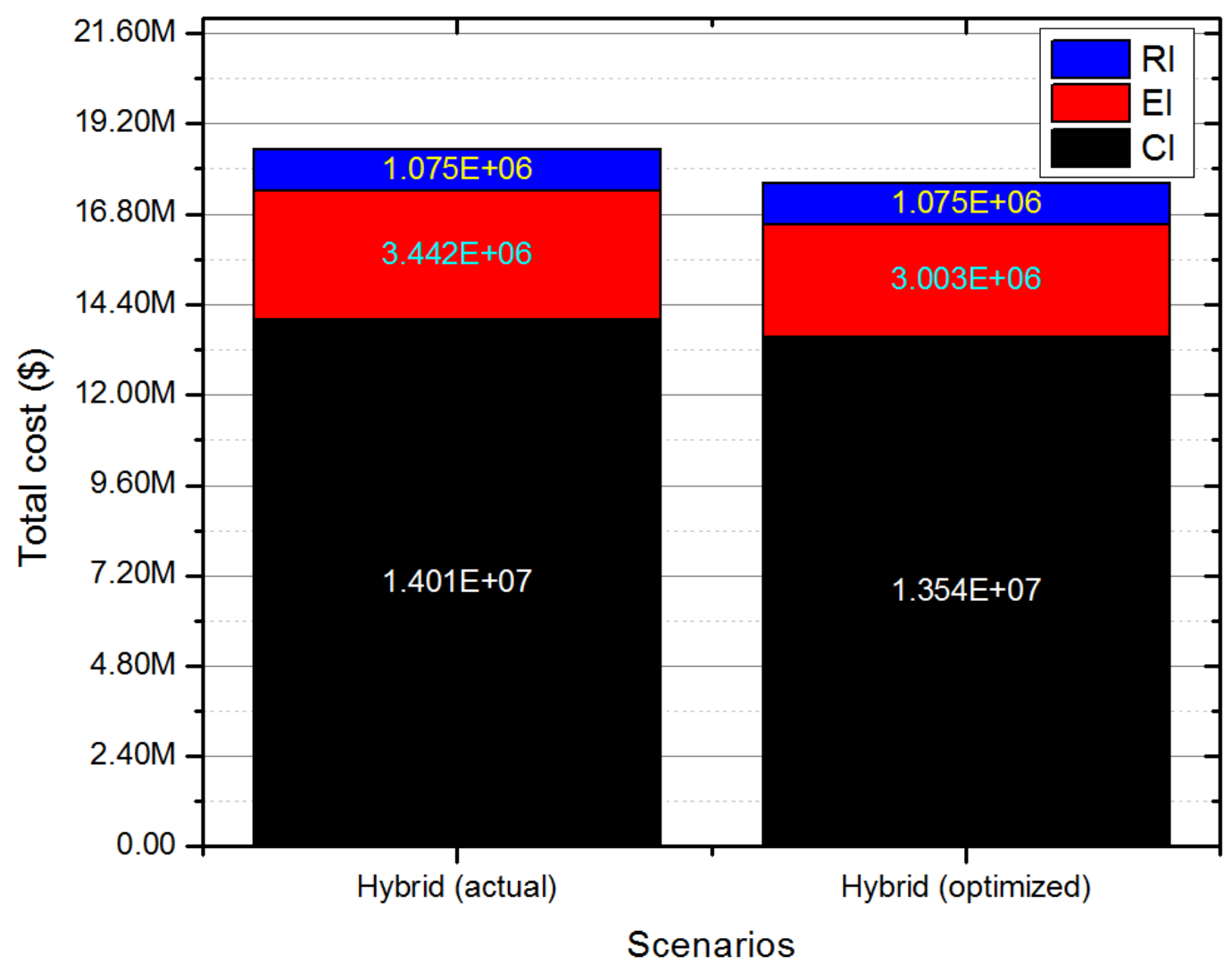

Fig. 14. Analysis results, compared to optimal scenarios. 
Table 11 Prices of emissions in accordance with EU nations [51].

\begin{tabular}{|c|c|c|c|c|c|c|}
\hline & & & & $\mathrm{PM}_{25}$ (exhaust) & & \\
\hline & NOx & NMVOC & $\mathrm{SO}_{2}$ & urban & outside & $\mathrm{CO}_{2}$ \\
\hline Austria & $\$ 10,266.00$ & $\$ 2,006.00$ & $\$ 9,794.00$ & $\$ 489,700.00$ & $\$ 32,804.00$ & - \\
\hline Belgium & $\$ 6,136.00$ & $\$ 2,950.00$ & $\$ 12,980.00$ & $\$ 498,196.00$ & $\$ 43,070.00$ & - \\
\hline Bulgaria & $\$ 2,124.00$ & $\$ 236.00$ & $\$ 1,180.00$ & $\$ 50,740.00$ & $\$ 5,192.00$ & - \\
\hline Cyprus & $\$ 590.00$ & $\$ 354.00$ & $\$ 2,360.00$ & $\$ 287,566.00$ & $\$ 9,676.00$ & - \\
\hline Czech Republic & $\$ 8,614.00$ & $\$ 1,180.00$ & $\$ 9,440.00$ & $\$ 298,068.00$ & $\$ 29,618.00$ & - \\
\hline Denmark & $\$ 5,192.00$ & $\$ 826.00$ & $\$ 6,136.00$ & $\$ 456,424.00$ & $\$ 21,476.00$ & $\$ 26.00$ \\
\hline Estonia & $\$ 944.00$ & $\$ 118.00$ & $\$ 2,124.00$ & $\$ 157,412.00$ & $\$ 10,620.00$ & - \\
\hline Finland & $\$ 944.00$ & $\$ 236.00$ & $\$ 2,124.00$ & $\$ 397,778.00$ & $\$ 13,216.00$ & $\$ 65.00$ \\
\hline France & $\$ 9,086.00$ & $\$ 1,652.00$ & $\$ 9,440.00$ & $\$ 462,796.00$ & $\$ 37,052.00$ & $\$ 25.00$ \\
\hline Germany & $\$ 11,328.00$ & $\$ 2,006.00$ & $\$ 12,980.00$ & $\$ 453,710.00$ & $\$ 35,400.00$ & - \\
\hline Greece & $\$ 944.00$ & $\$ 354.00$ & $\$ 1,652.00$ & $\$ 293,466.00$ & $\$ 16,520.00$ & - \\
\hline Hungary & $\$ 6,372.00$ & $\$ 1,062.00$ & $\$ 5,664.00$ & $\$ 240,484.00$ & $\$ 24,662.00$ & - \\
\hline Ireland & $\$ 4,484.00$ & $\$ 826.00$ & $\$ 5,664.00$ & $\$ 461,380.00$ & $\$ 19,352.00$ & $\$ 22.00$ \\
\hline Italy & $\$ 6,726.00$ & $\$ 1,298.00$ & $\$ 7,198.00$ & $\$ 438,488.00$ & $\$ 31,978.00$ & - \\
\hline Latvia & $\$ 1,652.00$ & $\$ 236.00$ & $\$ 2,360.00$ & $\$ 136,526.00$ & $\$ 10,148.00$ & - \\
\hline Lithuania & $\$ 2,124.00$ & $\$ 236.00$ & $\$ 2,832.00$ & $\$ 168,858.00$ & $\$ 13,452.00$ & - \\
\hline Luxembourg & $\$ 10,266.00$ & $\$ 3,186.00$ & $\$ 11,564.00$ & $\$ 792,370.00$ & $\$ 45,194.00$ & - \\
\hline Malta & $\$ 826.00$ & $\$ 472.00$ & $\$ 2,596.00$ & $\$ 289,572.00$ & $\$ 9,676.00$ & - \\
\hline Netherlands & $\$ 7,788.00$ & $\$ 2,242.00$ & $\$ 15,340.00$ & $\$ 498,550.00$ & $\$ 38,940.00$ & - \\
\hline
\end{tabular}

\subsubsection{Varying service routes (Scenario 3)}

The current study focused on a hybrid ship engaged in the UK coastal areas, hence the prices of emissions were guided by the UK market prices. However, as shown in Table 11, the wide range of emission prices across the EU nations suggests that the service area of the hybrid ship may also have an influence on the outcome of decision-making. The level of the change in the environmental impact according to different geometrical areas was investigated for two scenarios - one with the highest emission costs and the other with the lowest. 


\begin{tabular}{|c|c|c|c|c|c|c|}
\hline Norway & $\$ 2,360.00$ & $\$ 354.00$ & $\$ 2,950.00$ & $\$ 365,328.00$ & $\$ 14,160.00$ & $\$ 52.00$ \\
\hline Poland & $\$ 4,602.00$ & $\$ 708.00$ & $\$ 6,608.00$ & $\$ 205,910.00$ & $\$ 24,662.00$ & - \\
\hline Portugal & $\$ 1,534.00$ & $\$ 590.00$ & $\$ 4,130.00$ & $\$ 306,210.00$ & $\$ 18,172.00$ & $\$ 7.00$ \\
\hline Romania & $\$ 2,596.00$ & $\$ 472.00$ & $\$ 2,360.00$ & $\$ 34,456.00$ & $\$ 3,540.00$ & - \\
\hline Slovakia & $\$ 6,136.00$ & $\$ 826.00$ & $\$ 5,782.00$ & $\$ 229,156.00$ & $\$ 24,780.00$ & - \\
\hline Slovenia & $\$ 7,906.00$ & $\$ 1,652.00$ & $\$ 7,316.00$ & $\$ 310,222.00$ & $\$ 25,724.00$ & $\$ 19.00$ \\
\hline Spain & $\$ 3,068.00$ & $\$ 472.00$ & $\$ 5,074.00$ & $\$ 353,528.00$ & $\$ 19,470.00$ & - \\
\hline Sweden & $\$ 2,596.00$ & $\$ 354.00$ & $\$ 3,304.00$ & $\$ 416,068.00$ & $\$ 16,166.00$ & $\$ 131.00$ \\
\hline Switzerland & $\$ 10,856.00$ & $\$ 2,124.00$ & $\$ 10,384.00$ & $\$ 524,864.00$ & $\$ 34,692.00$ & $\$ 86.00$ \\
\hline United Kingdom & $\$ 4,602.00$ & $\$ 1,298.00$ & $\$ 7,788.00$ & $\$ 459,138.00$ & $\$ 28,674.00$ & $\$ 24.00$ \\
\hline
\end{tabular}

*Where maximum emission prices are highlighted with red while minimum prices are with green.

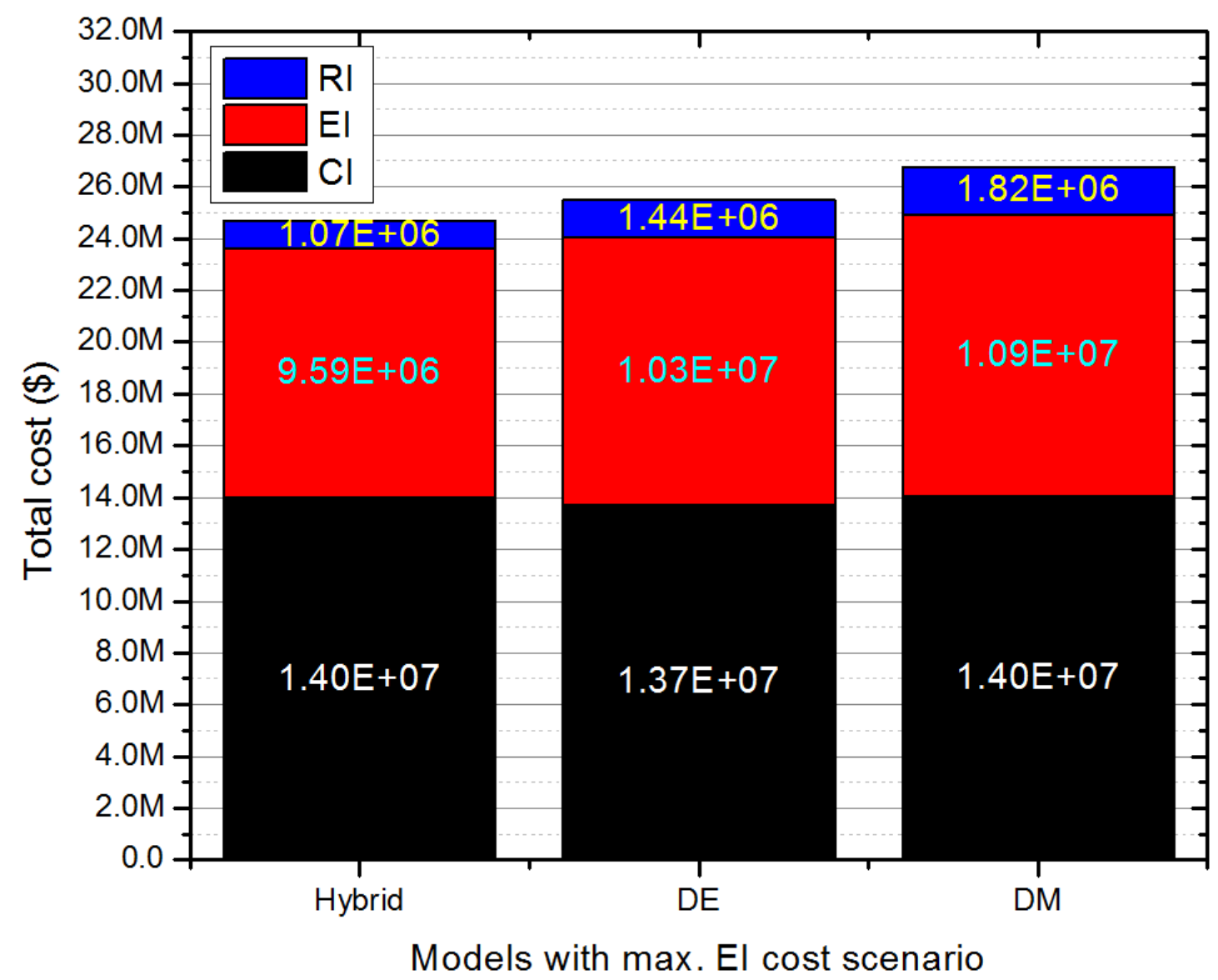

Fig. 15. Results with maximum EI cost scenario. 


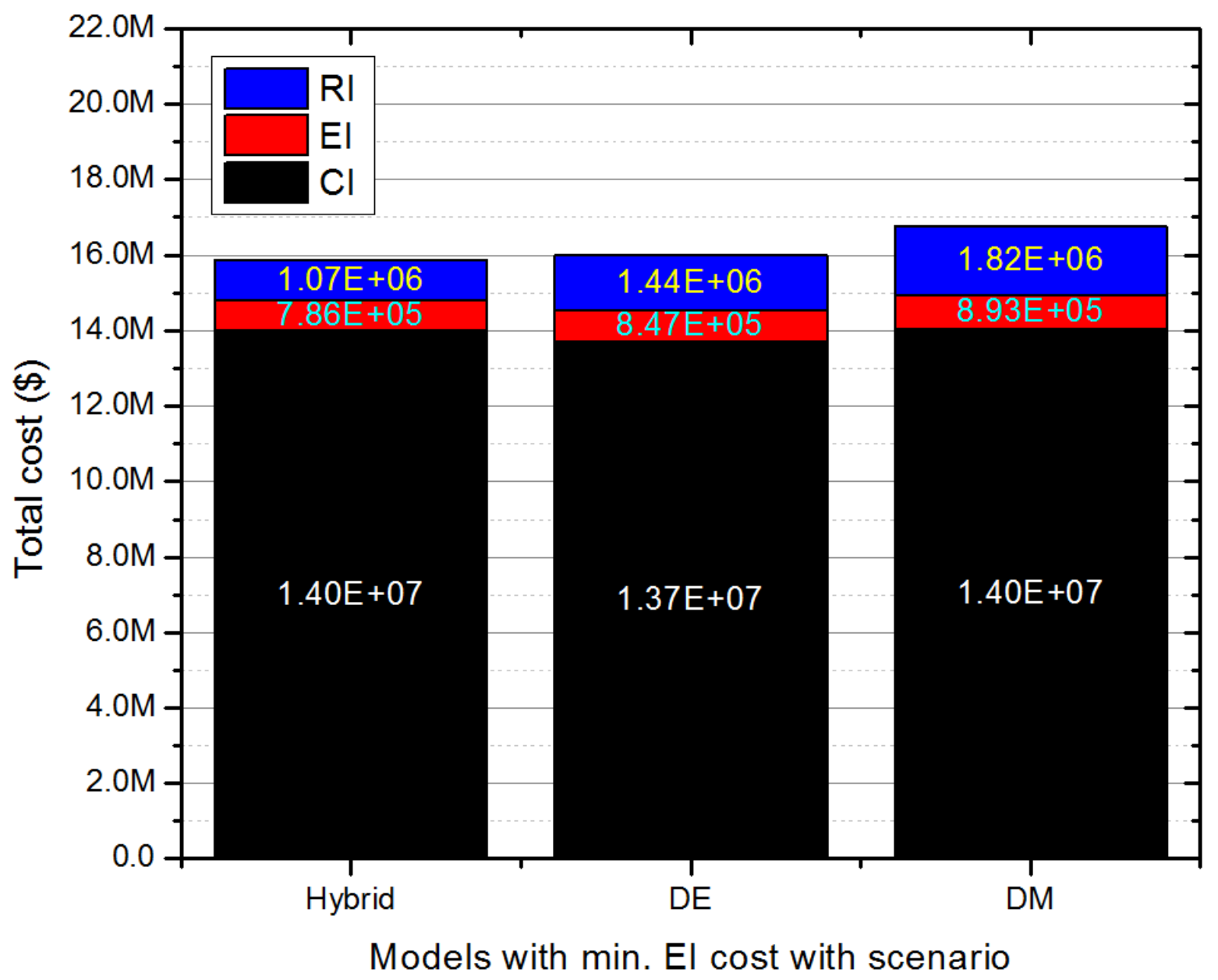

Fig. 16. Results with minimum EI cost scenario.

Fig. 15 and Fig. 16 summarize the influence of different environmental impacts on the total costs. The results indicate that the hybrid propulsion system was more advantageous than the other two options. The benefits were even more pronounced when the costs of environmental impact were highest.

\subsection{Comparison with conventional MCDA process}

In order to prove the merit of the proposed approach, this section compares the results obtained from the proposed method to those from conventional MCDA using the analytic hierarchy process (AHP). Fig. 17 shows the general concept of the AHP applicable to the 
purposed case studies. In this process, the impact of risk assessment remains in the form of RPNs, whilst those of economic assessment and environmental assessment are expressed in monetary value. To allow comparison of the different units the first step requires a normalization process where the values grouped in each criterion are compared to one another and converted into relative ratios $(\%)$. For example, if environmental impact for A1 model is $600 \mathrm{~K} \mathrm{GBP}$, for A2 model is $811 \mathrm{~K} \mathrm{GBP}$ and for A3 model is $1,140 \mathrm{~K} \mathrm{GBP}$, the normalized ratio will be $24 \% 31 \%$ and $45 \%$.

In order to reflect the decision-makers' priority, the analytic hierarchy process (AHP) was applied for scoring \& weighting factors. In the final step of this process, numerical priorities are assigned for each impact criteria. Through the AHP technique, a numerical weight or priority is derived for each impact criteria. Therefore, this number finally represents the level of importance on each impact criteria, concerned by decision-makers.

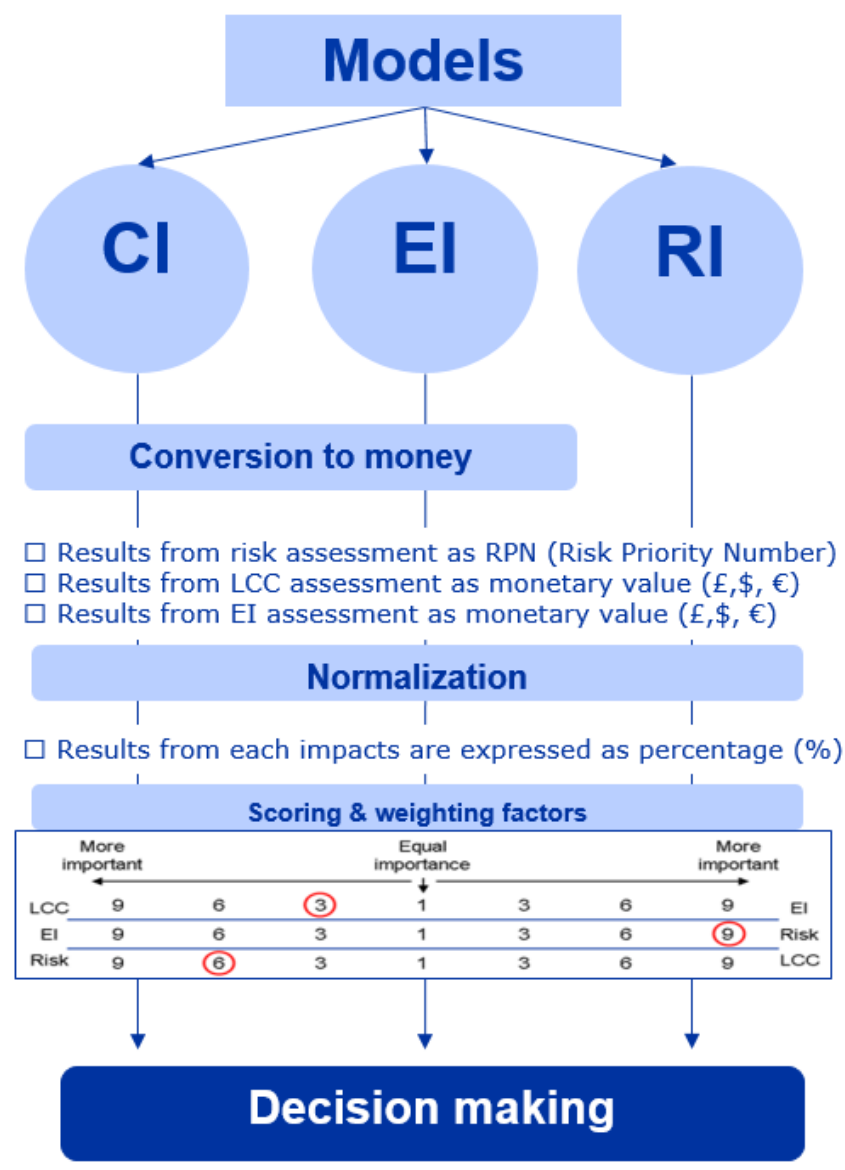


Fig. 17. Conventional MCDA using AHP method [46][55].

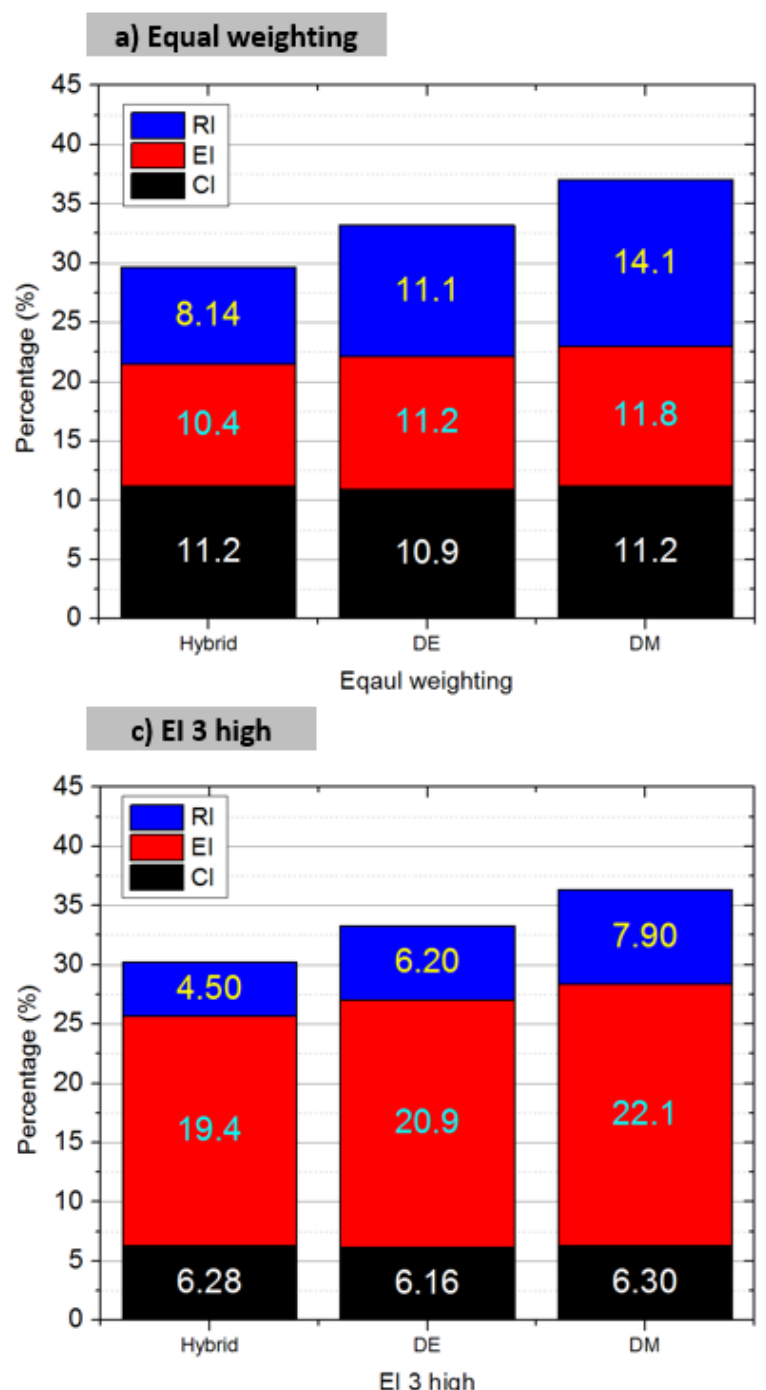

b) $\mathrm{Cl} 3$ high

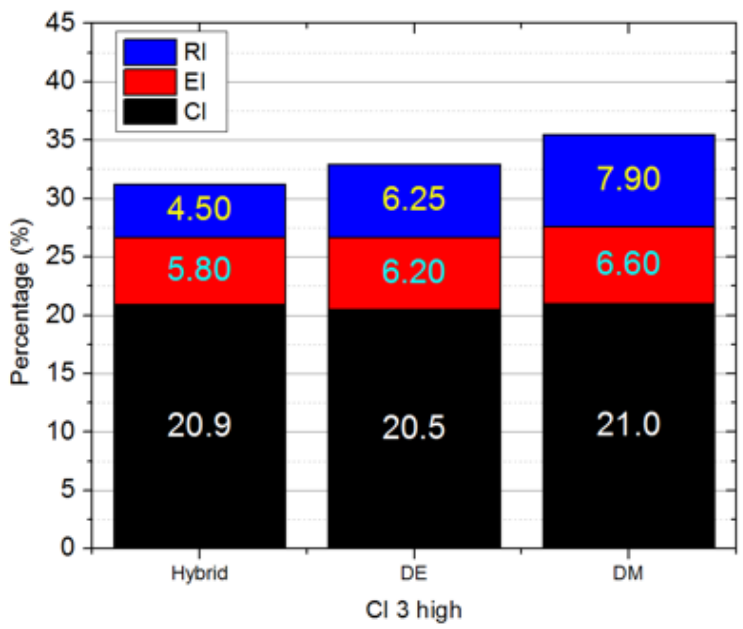

d) RI 3 high

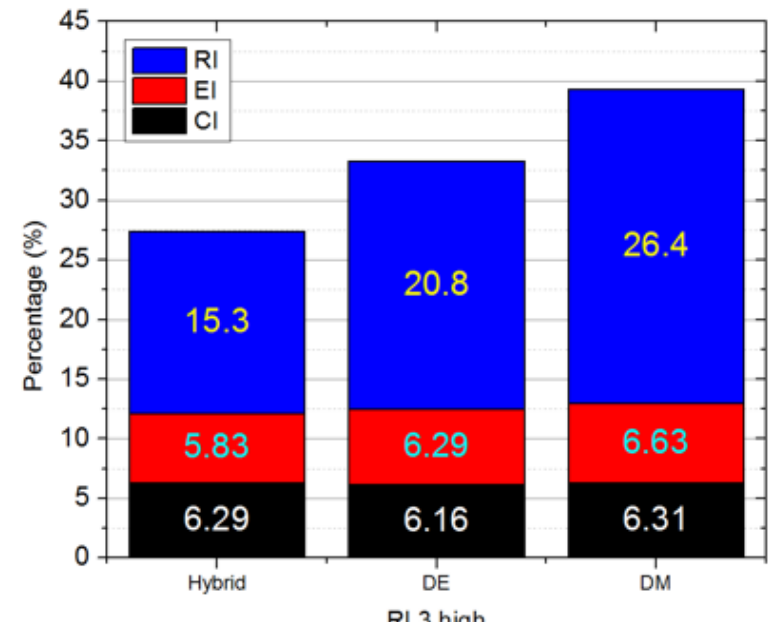

Fig. 18. Comparison of the results obtained from both the proposed method and conventional AHP method.

Fig. 18 presents the summary of the results obtained from the conventional AHP method. The underlying distinction between the proposed method and the conventional one was the unit of comparison: "cost (monetary value)" for the proposed method while "percentage" for the conventional one. In addition, conventional method required the extra process of scoring \& 
weighing factors. Fig. 18 a) shows the results when the equal weighing factor was applied to

\section{Discussion}

This paper presents an enhanced multi-criteria decision analysis (MCDA) to evaluate the performance of a hybrid ship compared with that of an equivalent ship with conventional propulsion systems. The enhanced MCDA adopted for this study converts incomparable units into monetary values, so that the impacts of each criterion can be compared.

The novelty of this research was centered at integrating the cost, environmental and risk perspectives without the loss of information, consequently finding the economic advantages of the hybrid propulsion system. 
It is generally accepted that DM propulsion systems are more efficient than DE propulsion system largely because the DE system is subject to electrical loss during the process of transmitting electricity generated from the diesel generator to the consumer. However, the investigation into the performance of the short route ferry in this paper revealed that the optimal operation of the hybrid system - the combination between the DE and the battery systems - would provide higher propulsion efficiency than the DM system.

It was also found that the process of the optimal scenario selection was an effective way to examine the impact of ship operational practices and emission prices on the final results. Based on the results, not only were optimal decisions achieved, but also general trends of parametric effects on the final trend were observed.

This paper has shown the subjectivity of the conventional MCDA process where stakeholder preferences may lead to a wrong conclusion. It is believed that the enhanced process will contribute to improving the reliability of MCDA, providing a simpler and more straightforward decision-making process.

The use of systematic decision-making process is still far limited in the marine industry. On the other hand, with a growing concern on the marine pollution, a series of stringent environmental regulations have been introduced in both international and local manners. To comply with them, the marine industry strives to develop rule-compliant technologies and systems; for example, to curb the $\mathrm{SO}_{\mathrm{x}}$ emission, three options - using marine gas oil (MGO); installation of scrubber system and using liquefied natural gas (LNG) - were introduced. Since a number of new and efficient systems and products are available for the ship operators, owners and stakeholders, proper decision making is an essential element for the marine industry which is striving to find ways to survive in severe market competitions.

Given this, it is believed that the enhanced process will contribute to a better understanding of the value of a particular system from multiple perspectives, providing a simple and reliable 
decision-making process. Therefore, it is entirely conceivable that a good decision-making process will provide insight to reduce design and production costs, thereby to produce reliable ships. Nevertheless, the application of the proposed MCDA framework is not necessarily limited to the hybrid ships or marine systems. The method can be applied to any other products and technologies across a wide range of industries where good decisionmaking is important.

\section{Conclusions}

1) The drawbacks of the conventional normalization and weighting factor process of conventional MCDA were identified; any criterion is highly sensitive to the weight given to each of those components, thereby it has the potential to mislead the conclusion.

2) The effectiveness of the enhanced MCDA was demonstrated in a way that the integration of the unit of analysis could improve the reliability of outcomes by eliminating the conventional normalization and weighting factor process, thereby reducing the subjectivity of decision makers.

3) The new principle of converting qualitative risk values (RPN number) into the quantitative monetary values was shown practicable and particularly effective in the enhanced MCDA.

4) The case study with the enhanced MCDA approach has shown that the performance of the hybrid system in terms of aspects: economy, environment, and risk. Research findings to support the performance of the hybrid system can be summarized as below;

- Relatively higher initial costs of the hybrid system were compensated by the cost reduction in energy consumption and engine maintenance. 
- The hybrid system was found to contribute to cleaner shipping as using less fuel leads directly to lower emissions.

- The hybrid system was shown to enhance the safety and reliability of the propulsion system.

\section{Acknowledgement}

The authors wish to thank the Caledonian Mac Brayne (Calmac Ferry Ltd) Ferries for providing the data used in this paper. The authors also gratefully acknowledge that the research presented in this paper was partially generated as part of the HORIZON 2020 SHIPLYS (Ship life cycle software solutions) Project, Grant agreement number 690770.

\section{References}

[1] Brandsaeter A, Valoen L-O, Mollestad E, Haugom G-P. In focus - The future is Hybrid. Hamburg, Germany: DNV GL. 2015

[2] Andersen P, \& Rzadki, W. Hybrid ship propulsion system. Google Patents. 2007.

[3] Ferguson Marine Engineering Ltd. 2016.

[4] Lindstad HE, Sandaas I. Emission and fuel reduction for offshore support vessels through hybrid technology. Journal of Ship Production and Design. 2016; 32: 195-205. 
[5] Ling-Chin J, Roskilly AP. Investigating the implications of a new-build hybrid power assessment case study. Applied Energy. 2016; 181: 416-34.

[6] Dedes EK, Hudson DA, Turnock SR. Investigation of Diesel Hybrid systems for fuel oil reduction in slow speed ocean going ships. Energy. 2016; 114: 444-56.

[7] Wang H, Ougz E, Jeong B, Zhou P. Optimisation of Operational Modes of Short-Route Hybrid Ferry: A Life Cycle Assessment Case Study. IMAM 2017 - International Maritime Association of the Mediterranean. Lisbon 2017.

[8] Lan H, Wen S, Hong Y-Y, David CY, Zhang L. Optimal sizing of hybrid PV/diesel/battery in ship power system. Applied Energy. 2015; 158: 26-34.

[9] Wen S, Lan H, Hong Y-Y, David CY, Zhang L, Cheng P. Allocation of ESS by interval optimization method considering impact of ship swinging on hybrid PV/diesel ship power system. Applied Energy. 2016; 175: 158-67.

[10] Diab F, Lan H, Ali S. Novel comparison study between the hybrid renewable energy systems on land and on ship. Renewable and Sustainable Energy Reviews. 2016; 63: 452-63.

[11] Geertsma R, Negenborn R, Visser K, Hopman J. Design and control of hybrid power and propulsion systems for smart ships: A review of developments. Applied Energy. 2017;194:30-54.

[12] Geertsma R, Negenborn R, Visser K, Hopman J. Torque control for diesel mechanical and hybrid propulsion for naval vessels. Proceedings of the 13th international naval engineering conference Bristol, UK. 2016:476-92.

[13] Geertsma R, Negenborn R, Visser K, Hopman J. Parallel control for hybrid propulsion of multifunction ships. IFAC-PapersOnLine. 2017;50:2296-303. 
[14] Veneri O, Migliardini F, Capasso C, Corbo P. Overview of electric propulsion and generation architectures for naval applications. Electrical Systems for Aircraft, Railway and Ship Propulsion (ESARS), 2012: IEEE; 2012:1-6.

[15] Roskilly A, Palacin R, Yan J. Novel technologies and strategies for clean transport systems. Applied Energy. 2015:563-6.

[16] Zhao F, Yang W, Tan WW, Yu W, Yang J, Chou SK. Power management of vessel propulsion system for thrust efficiency and emissions mitigation. Applied Energy. 2016;161:124-32.

[17] Aneke M, Wang M. Energy storage technologies and real life applications-A state of the art review. Applied Energy. 2016;179:350-77.

[18] Jeong B, Wang H, Oguz E, Zhou P. An Effective Framework for Life Cycle and Cost Assessment for Marine Vessels Aiming to Select Optimal Propulsion Systems. Journal of Cleaner Production. 2018;187:111-130.

[19] Palmer K, Tate JE, Wadud Z, Nellthorp J. Total cost of ownership and market share for hybrid and electric vehicles in the UK, US and Japan. Applied Energy. 2018;209:108-19.

[20] Hutchinson T, Burgess S, Herrmann G. Current hybrid-electric powertrain architectures: Applying empirical design data to life cycle assessment and whole-life cost analysis. Applied Energy. 2014;119:314-29.

[21] Wheelan C. Naked statistics: Stripping the dread from the data: WW Norton \& Company; 2013.

[22] Fishburn PC. Conjoint measurement in utility theory with incomplete product sets. Journal of Mathematical Psychology. 1967; 4: 104-19.

[23] Løken E. Use of multicriteria decision analysis methods for energy planning problems. Renewable and Sustainable Energy Reviews. 2007; 11: 1584-95.

[24] Canbolat YB, Chelst K, Garg N. Combining decision tree and MAUT for selecting a country for a global manufacturing facility. Omega. 2007; 35: 312-25. 
[25] Bentes AV, Carneiro J, da Silva JF, Kimura H. Multidimensional assessment of organizational performance: Integrating BSC and AHP. Journal of business research. 2012; 65: 1790-9.

[26] Okeola O, Sule B. Evaluation of management alternatives for urban water supply system using Multicriteria Decision Analysis. Journal of King Saud University-Engineering Sciences. 2012; 24: 19-24.

[27] Ambrasaite I, Barfod MB, Salling KB. MCDA and risk analysis in transport infrastructure appraisals: The rail baltica case. Procedia-Social and Behavioral Sciences. 2011; 20: 944-53.

[28] Özcan EC, Ünlüsoy S, Eren T. A combined goal programming-AHP approach supported with TOPSIS for maintenance strategy selection in hydroelectric power plants. Renewable and Sustainable Energy Reviews. 2017; 78: 1410-23.

[29] Rangone A. An analytical hierarchy process framework for comparing the overall performance of manufacturing departments. International Journal of Operations \& Production Management. 1996; 16: 104-19.

[30] Linkov I, Seager TP. Coupling multi-criteria decision analysis, life-cycle assessment, and risk assessment for emerging threats. ACS Publications; 2011.

[31] Basurko OC, Mesbahi E. Methodology for the sustainability assessment of marine technologies. Journal of cleaner production. 2014; 68: 155-64.

[32] Niekamp S, Bharadwaj UR, Sadhukhan J, Chryssanthopoulos MK. A multi-criteria decision support framework for sustainable asset management and challenges in its application. Journal of Industrial and Production Engineering. 2015; 32: 23-36. 
[33] Yuan J, Ng SH. Emission reduction measures ranking under uncertainty. Applied Energy. 2017; 188: 270-9.

[34] Dong J, Chi Y, Zou D, Fu C, Huang Q, Ni M. Energy-environment-economy assessment of waste management systems from a life cycle perspective: Model development and case study. Applied Energy. 2014; 114: 400-8.

[35] Höfer T, Sunak Y, Siddique H, Madlener R. Wind farm siting using a spatial Analytic Hierarchy Process approach: A case study of the Städteregion Aachen. Applied energy. 2016; 163: $222-43$.

[36] Sánchez-Lozano J, García-Cascales M, Lamata M. GIS-based onshore wind farm site selection using Fuzzy Multi-Criteria Decision-making methods. Evaluating the case of Southeastern Spain. Applied Energy. 2016; 171: 86-102.

[37] Wang Z, Lei T, Chang X, Shi X, Xiao J, Li Z, et al. Optimization of a biomass briquette fuel system based on grey relational analysis and analytic hierarchy process: A study using cornstalks in China. Applied Energy. 2015; 157: 523-32.

[38] Sultana A, Kumar A. Optimal siting and size of bioenergy facilities using geographic information system. Applied Energy. 2012; 94: 192-201.

[39] Comber A, Dickie J, Jarvis C, Phillips M, Tansey K. Locating bioenergy facilities using a modified GIS-based location-allocation-algorithm: Considering the spatial distribution of resource supply. Applied Energy. 2015; 154: 309-16.

[40] Handfield R, Walton SV, Sroufe R, Melnyk SA. Applying environmental criteria to supplier assessment: A study in the application of the Analytical Hierarchy Process. European journal of operational research. 2002; 141: 70-87. 
[41] Chan FS. Interactive selection model for supplier selection process: an analytical hierarchy process approach. International Journal of Production Research. 2003; 41: 3549-79.

[42] Wang J-J, Jing Y-Y, Zhang C-F, Zhao J-H. Review on multi-criteria decision analysis aid in sustainable energy decision-making. Renewable and Sustainable Energy Reviews. 2009; 13: 2263-78.

[43] Ma J, Fan Z-P, Huang L-H. A subjective and objective integrated approach to determine attribute weights. European journal of operational research. 1999; 112: 397-404.

[44] Barone M, Begovic E, Bertorello C, Stella M. Preference communication in multiattribute procedures for optimised ship design. 12th International Congress of the International Maritime Association of the Mediterranean, IMAM2005.

[45] Velasquez M, Hester PT. An analysis of multi-criteria decision-making methods. International Journal of Operations Research. 2013; 10: 56-66.

[46] Cui X, Bharadwaj U, Zhou P. A framework for Multi-Criteria Decision Analysis (MCDA) applied to conceptual stage of ship design. IMAM 2017 - International Maritime Association of the Mediterranean. Lisbon: Taylor \& Francis Group; 2017.

[47] Dawes RM. The robust beauty of improper linear models in decision-making. American psychologist. 1979; 34: 571.

[48] IMO. Third IMO Greenhouse Gas Study 2014. London: IMO; 2015.

[49] Bieckel P, Friedrich R, Burgess A, Fagiani P, Hunt A, Jong Gd, et al. HEATCO. Developing Harmonised European Approaches for Transport Costing and Project Assessment, Deliverable 5, Proposal for Harmonised Guidelines. Contract No FP6-2002SSP-1/502481. 2006. 
[50] Jiang L, Kronbak J, Christensen LP. The costs and benefits of sulphur reduction measures: Sulphur scrubbers versus marine gas oil. Transportation Research Part D: Transport and Environment. 2014; 28: 19-27.

[51] Maibach M, Schreyer C, Sutter D, Van Essen H, Boon B, Smokers R, et al. Handbook on estimation of external costs in the transport sector. CE Delft. 2008.

[52] Giardina M, Morale M. Safety study of an LNG regasification plant using an FMECA and HAZOP integrated methodology. Journal of Loss Prevention in the Process Industries. $2015 ; 35: 35-45$.

[53] Ship \& Bunker. World Bunker Prices. 2017.

[54] Scottish power 2015. Fixed Price Energy January 2015.

[55] Cui X, Bharadwaj U. TWI Approach to MCDA using Risk, LCC, and Environmental Impact as Input 2017. 